\title{
A new methodology to simulate subglacial deformation of water-saturated granular material
}

\author{
A. Damsgaard ${ }^{1}$, D. L. Egholm ${ }^{1}$, J. A. Piotrowski ${ }^{1}$, S. Tulaczyk ${ }^{2}$, N. K. Larsen ${ }^{1,3}$, and C. F. Brædstrup ${ }^{1}$ \\ ${ }^{1}$ Department of Geoscience, Aarhus University, 8000 Aarhus C, Denmark \\ ${ }^{2}$ Department of Earth and Planetary Sciences, University of California, Santa Cruz, California 95064, USA \\ ${ }^{3}$ Centre for GeoGenetics, Natural History Museum of Denmark, University of Copenhagen, 1350 Copenhagen K, Denmark
}

Correspondence to: A. Damsgaard (anders.damsgaard@geo.au.dk)

Received: 16 June 2015 - Published in The Cryosphere Discuss.: 13 July 2015

Revised: 26 October 2015 - Accepted: 13 November 2015 - Published: 20 November 2015

\begin{abstract}
The dynamics of glaciers are to a large degree governed by processes operating at the ice-bed interface, and one of the primary mechanisms of glacier flow over soft unconsolidated sediments is subglacial deformation. However, it has proven difficult to constrain the mechanical response of subglacial sediment to the shear stress of an overriding glacier. In this study, we present a new methodology designed to simulate subglacial deformation using a coupled numerical model for computational experiments on grainfluid mixtures. The granular phase is simulated on a per-grain basis by the discrete element method. The pore water is modeled as a compressible Newtonian fluid without inertia. The numerical approach allows close monitoring of the internal behavior under a range of conditions.

Our computational experiments support the findings of previous studies where the rheology of a slowly deforming water-saturated granular bed in the steady state generally conforms to the rate-independent plastic rheology. Before this so-called critical state, deformation is in many cases accompanied by volumetric changes as grain rearrangement in active shear zones changes the local porosity. For previously consolidated beds porosity increases can cause local pore-pressure decline, dependent on till permeability and shear rate. We observe that the pore-water pressure reduction strengthens inter-granular contacts, which results in increased shear strength of the granular material. In contrast, weakening takes place when shear deformation causes consolidation of dilated sediments or during rapid fabric development. Both processes of strengthening and weakening depend inversely on the sediment permeability and are tran-
\end{abstract}

sient phenomena tied to the porosity changes during the early stages of shear.

We find that the transient strengthening and weakening in turn influences the distribution of shear strain in the granular bed. Dilatant strengthening has the ability to distribute strain during early deformation to large depths, if sediment dilatancy causes the water pressure at the ice-bed interface to decline. Oppositely, if the ice-bed interface is hydrologically stable the strengthening process is minimal and instead causes shallow deformation. The depth of deformation in subglacial beds thus seems to be governed by not only local grain and pore-water feedbacks but also larger-scale hydrological properties at the ice base.

\section{Introduction}

The coupled mechanical response of ice, water, and sediment can control the flow of glaciers residing on deformable sediment (e.g., Alley et al., 1987; Bindschadler et al., 2001; Clarke, 2005; Bougamont et al., 2011; Turrin et al., 2014). This is clearly expressed by ice streams in Greenland and Antarctica, where low levels of basal friction enable high flow rates. These ice streams are of particular interest, since they are large contributors to the polar ice sheet mass balance (e.g., Rignot and Thomas, 2002).

Although most flow-limiting friction of ice streams terminating into ice shelves is likely provided by ice shelf buttressing (De Angelis and Skvarca, 2003; Rignot et al., 2004; Dupont and Alley, 2005), the disintegration of these 
ice shelves leaves lateral (Whillans and van der Veen, 1997; Tulaczyk et al., 2000b; Price et al., 2002) and basal friction (Alley, 1993; MacAyeal et al., 1995; Stokes et al., 2007; Sergienko and Hindmarsh, 2013) as the main mechanical components resisting the flow. A fundamental understanding of subglacial dynamics is a requirement for our ability to predict future response of the ice sheets to climate change.

The pressure and flow of pore water in the subglacial bed can influence subglacial deformation in a number of ways. Assuming a Mohr-Coulomb constitutive relation of the basal till strength, an increase in pore-water pressure weakens the bed by reducing the effective stress, and this may facilitate basal movement if the driving shear stresses become sufficient to overcome the sediment yield strength (Kamb, 1991; Iverson et al., 1998; Tulaczyk et al., 2000a; Fischer and Clarke, 2001; Kavanaugh and Clarke, 2006).

If the hydraulic diffusivity of the bed is sufficiently low relative to the rate of deformation, a modulation of the porewater pressure at the ice-bed interface is, over time, carried into the subglacial bed, resulting in variable internal yield strength and ultimately variable shear strain rates with depth (Tulaczyk, 1999; Tulaczyk et al., 2000a; Kavanaugh and Clarke, 2006). Owing to local volumetric changes, variations from the hydrostatic fluid pressure distribution can be created inside the sediment by the onset and halt of granular deformation. This influences the local effective pressure and, in turn, the sediment yield strength (e.g., Iverson et al., 1998).

In the case of non-planar ice-bed geometry, excess porewater pressures can develop on the stoss side of objects ploughing through a subglacial bed (Iverson et al., 1994; Iverson, 1999; Thomason and Iverson, 2008). The elevated pore-water pressure weakens the sediment by lowering the effective stress, resulting in a net strain-rate weakening rheology (e.g., Iverson et al., 1998; Fischer et al., 2001; Clark et al., 2003; Iverson, 2010), which has been associated with the stick-slip behavior of Whillans Ice Stream (Winberry et al., 2009).

Early field studies suggested a strain-rate strengthening Bingham or slightly non-linear viscous rheology of till (Boulton and Hindmarsh, 1987), which has been used to simplify analytical and numerical modeling of till mechanics (e.g., Alley et al., 1987; Hindmarsh, 1998; Fowler, 2000). Laboratory studies have, however, strongly favored the notion of till having a plastic, Mohr-Coulomb rheology, with a very small rate dependence in the case of critical-state deformation (Kamb, 1991; Iverson et al., 1998; Tulaczyk et al., 2000a; Rathbun et al., 2008). This Mohr-Coulomb rheology is also supported by field investigations (Truffer et al., 2000; Kavanaugh and Clarke, 2006). However, a rate-weakening rheology is expected in the case where obstacles plough through a soft and deformable bed (Iverson et al., 1994; Iverson, 1999; Thomason and Iverson, 2008).

The low viscosity of water facilitates flow at low stress and can only be expected to influence the overall strength

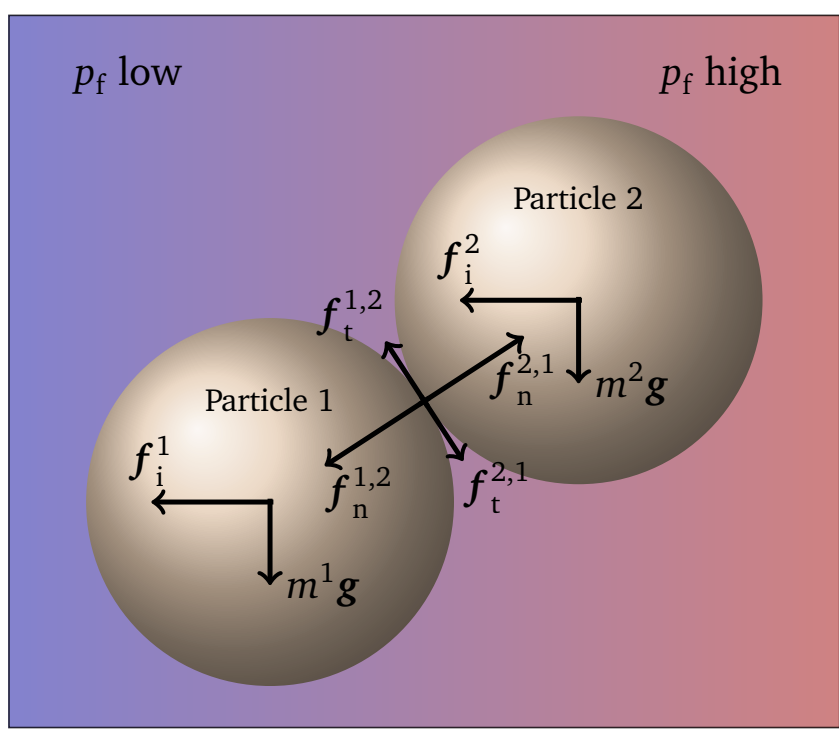

Figure 1. Schematic representation of body and surface forces of two non-rotating and interacting particles submerged in a fluid with a pressure gradient.

of subglacial materials in a few select scenarios, e.g., when pore-water flow due to porosity change in early stages of shear deformation is limited by low hydraulic diffusivities (e.g., Iverson, 2010). The mechanics of coupled granularfluid mixtures have previously been numerically investigated for studies of fluidized beds (e.g., Anderson and Jackson, 1967; Gidaspow et al., 1992; Hoomans et al., 1996; Xu and Yu, 1997; McNamara et al., 2000; Feng and Yu, 2004; Jajcevic et al., 2013), the stability of inclined, fluid-immersed granular materials (e.g., Topin et al., 2011; Mutabaruka et al., 2014), mechanics during confined deformation (e.g., Goren et al., 2011; Catalano et al., 2014), debris flow (e.g., Hutter et al., 1994; Mangeney et al., 2007; Goren et al., 2011), and for the design of industrial components, e.g., hydrocyclones (e.g., Wang et al., 2007; Zhou et al., 2010), or silos and hoppers (Kloss et al., 2012).

In this study, we explore the interaction between the fluid and granular phases in water-saturated consolidated particle assemblages undergoing slow shear deformation. A dry granular assemblage deforms rate-independently in a pseudostatic manner when deformational rates are sufficiently low (GDR-MiDi, 2004; Damsgaard et al., 2013). Critical-state deformation of water-saturated granular materials is rate independent during slow shear, but transient changes in pore pressure may cause initiation of liquefaction at higher shear velocities (Goren et al., 2011). The particle-fluid mixture is in this study sheared at velocities and stresses comparable to those found in subglacial settings. The computational approach allows for investigating the internal granular mechanics and feedbacks during progressive shear deformation.

In the following section, we present the details of the numerical implementation of particle-fluid flow and describe 
the experimental setup. We then present and discuss the modeled deformational properties of the particle-fluid mixture. Finally, we analyze how the fluid influences formation of shear zones and under which conditions deformation is rate dependent.

\section{Methods}

\subsection{The granular model}

We use the discrete element method (DEM) (Cundall and Strack, 1979) to simulate the granular deformation. With the DEM, particles are treated as separate, cohesionless entities, which interact by soft-body deformation defined by a prescribed contact law. The contact mechanics are micromechanically parameterized. The temporal evolution is handled by integration of the momentum equations of translation:

$m^{i} \frac{\partial^{2} \boldsymbol{x}^{i}}{\partial t^{2}}=\underbrace{m^{i} \boldsymbol{g}}_{\text {Gravity }}+\overbrace{\sum_{j}\left(\boldsymbol{f}_{\mathrm{n}}^{i j}+\boldsymbol{f}_{\mathrm{t}}^{i j}\right)}^{\text {Contact forces }}+\boldsymbol{f}_{\mathrm{i}}^{i}$,

and rotation:

$$
I^{i} \frac{\partial^{2} \boldsymbol{\Omega}^{i}}{\partial t^{2}}=\underbrace{\sum_{j}\left(-\left(r^{i}+\frac{\delta_{\mathrm{n}}^{i j}}{2}\right) \boldsymbol{n}^{i j} \times \boldsymbol{f}_{\mathrm{t}}^{i j}\right)}_{\text {Contact torques }} .
$$

$i$ and $j$ are particle indexes, $m$ is the particle mass, $I$ is the particle rotational inertia, and $\boldsymbol{x}$ and $\boldsymbol{\Omega}$ are linear and rotational particle positions, respectively. The model considers the transient kinematics during time $t$. Gravitational acceleration is included as the vector $\boldsymbol{g}$. The inter-particle contact force vectors are denoted $\boldsymbol{f}_{\mathrm{n}}$ and $\boldsymbol{f}_{\mathrm{t}}$ in the normal and tangential direction relative to the contact interface. The particle radius is included as $r$. The fluid-particle interaction force is denoted $\boldsymbol{f}_{\mathrm{i}}$ (Fig. 1), and the inter-particle normal vector is termed $\boldsymbol{n}$. Here, $\delta_{\mathrm{n}}$ is the virtual inter-particle overlap at the contact, scaling the compressive strain of the particle. The inter-particle contact forces are determined by a linear-elastic contact model causing repulsion between particle pairs and providing frictional contact strength. The elastic stiffness is $k_{\mathrm{n}}$ in the normal direction to the contact and $k_{\mathrm{t}}$ parallel (tangential) to the contact interface. The magnitude of the tangential force $f_{\mathrm{t}}$ is limited by the Coulomb frictional coefficient $\mu$ (Cundall and Strack, 1979; Luding, 2008; Radjaï and Dubois, 2011; Damsgaard et al., 2013). The bulk Coulomb friction coefficient of a granular assemblage depends on the elastic properties, the inter-particle frictional coefficient, and the granular packing arrangement (e.g., Booth et al., 2014).

$$
\begin{aligned}
\boldsymbol{f}_{\mathrm{n}}^{i j}= & -k_{\mathrm{n}} \delta_{\mathrm{n}}^{i j} \boldsymbol{n}^{i j} \text { and } \boldsymbol{f}_{\mathrm{t}}^{i j}= \\
& -\max \left\{k_{\mathrm{t}}\left\|\boldsymbol{\delta}_{\mathrm{t}}^{i j}\right\|, \mu\left\|\boldsymbol{f}_{\mathrm{n}}^{i j}\right\|\right\} \frac{\delta_{\mathrm{t}}^{i j}}{\left\|\delta_{\mathrm{t}}^{i j}\right\|}
\end{aligned}
$$

The vector $\boldsymbol{\delta}_{\mathrm{t}}$ is the tangential displacement on the interparticle interface when corrected for contact rotation. In the case of slip, the length of $\boldsymbol{\delta}_{\mathrm{t}}$ is adjusted to a length consistent with Coulomb's condition $\left(\left\|\boldsymbol{\delta}_{\mathrm{t}}\right\|=-\mu\left\|\boldsymbol{f}_{\mathrm{n}}\right\| / k_{\mathrm{t}}\right.$ ) (Luding, 2008; Radjaï and Dubois, 2011). The linear elasticity allows temporal integration with a constant time step length $\Delta t$.

\subsection{The fluid model}

The inter-particle fluid is handled by using conventional continuum mechanics. The implementation follows the compressible Darcian flow model presented by Goren et al. (2011). This approach was favored over a full Navier-Stokes solution of fluid flow (Gidaspow, 1994; Zhu et al., 2007; Zhou et al., 2010; Kloss et al., 2012) because it allows for convenient parameterization of the hydrological permeabilities. The model assumes insignificant fluid inertia, which is appropriate for subglacial settings. Fluid compressibility is only important under undrained or very low-permeability conditions (e.g., Goren et al., 2011). We include fluid compressibility since the numerical method does not require us to impose the common simplification of incompressibility.

The volumetric fraction of the fluid phase (the porosity, $\phi$ ) is incorporated in the Eulerian formulations of the compressible continuity equation and momentum equation using the local average method (Anderson and Jackson, 1967; Xu and $\mathrm{Yu}, 1997)$. The Darcy constitutive equation is used for conserving momentum (Eq. 5) (McNamara et al., 2000; Goren et al., 2011):

$$
\begin{aligned}
& \frac{\partial p_{\mathrm{f}}}{\partial t}=\underbrace{\frac{1}{\beta_{\mathrm{f}} \phi \mu_{\mathrm{f}}} \nabla \cdot\left(k \nabla^{2} p_{\mathrm{f}}+\nabla p_{\mathrm{f}} \cdot \nabla k\right)}_{\text {Spatial diffusion }} \\
&+\underbrace{\frac{1}{\beta_{\mathrm{f}} \phi(1-\phi)}\left(\frac{\partial \phi}{\partial t}+\overline{\boldsymbol{v}}_{\mathrm{p}} \cdot \nabla \phi\right)}_{\text {Particle forcing }} \\
&\left(\boldsymbol{v}_{\mathrm{f}}-\boldsymbol{v}_{\mathrm{p}}\right) \phi=-\frac{k}{\mu_{\mathrm{f}}} \nabla p_{\mathrm{f}},
\end{aligned}
$$

where $\boldsymbol{v}_{\mathrm{f}}$ is the fluid velocity, $\boldsymbol{v}_{\mathrm{p}}$ is the particle velocity, and $k$ is the hydraulic permeability estimated from the local porosity. The adiabatic fluid compressibility is denoted $\beta_{\mathrm{f}}$, and $\mu_{\mathrm{f}}$ is the dynamic fluid viscosity. The continuity equation (Eq. 4) is in the form of a transient diffusion equation with the forcing term acting as a source/sink for the fluid pressure. The pressure, $p_{\mathrm{f}}$, is the pressure deviation from the hydrostatic pressure distribution. This pressure deviation is some- 

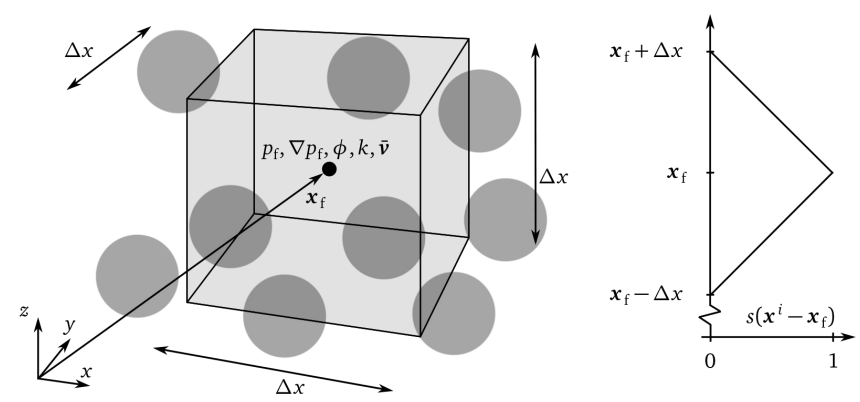

Figure 2. Left: a cell in the fluid grid. The node for pressure $\left(p_{\mathrm{f}}\right)$, the gradient of fluid pressure $\left(\nabla p_{\mathrm{f}}\right)$, porosity $(\phi)$, permeability $(k)$, and average grain velocity $(\overline{\boldsymbol{v}})$ are calculated at the cell center. Right: the weight function (Eq. 6) at various distances.

times referred to as the excess pressure. We refrain from using this term, as it may be misleading for pressures that are smaller than the hydrostatic value.

The simulation domain is discretized in a regular rectilinear orthogonal grid. The pressure is found using the CrankNicolson method of mixed explicit and implicit temporal integration, which is unconditionally stable and second-order accurate in time and space (e.g., Patankar, 1980; Ferziger and Perić, 2002; Press et al., 2007). The implicit solution is obtained using the iterative Jacobi relaxation method (e.g., Ferziger and Perić, 2002; Press et al., 2007; Gerya, 2010), which is light on memory requirements and ideal in terms of parallelism for our graphics processing unit (GPU) implementation, although not optimal in terms of convergence. The numerical solution is continuously checked by the Courant-Friedrichs-Lewy condition (Courant et al., 1967). The partial derivatives are approximated by finite differences.

\subsection{The granular-fluid coupling}

The particle and fluid algorithms interact by direct forcings (Eqs. 1 and 4) and through measures of porosity and permeability (Tsuji et al., 1992, 1993; Xu et al., 2001; Zhu et al., 2007; Goren et al., 2011).

\subsubsection{Porosity}

The local porosity is determined at the fluid cell center. For a cell with a set of $N$ grains in its vicinity, it is determined by inverse-distance weighting the grains using a bilinear interpolation scheme (McNamara et al., 2000; Goren et al., 2011). The weight function $s$ has the value 1 at the cell center and decreases linearly to 0 at a distance equal to the cell width
( $\Delta x$, Fig. 2):

$$
\begin{aligned}
& \phi\left(\boldsymbol{x}_{\mathrm{f}}\right)=1-\frac{\sum_{i \in N} s^{i} V_{\mathrm{g}}^{i}}{\Delta x^{3}} \\
& s^{i}=\left\{\Pi_{d=1}^{3}\left[1-\frac{\left|\boldsymbol{x}_{d}^{i}-\boldsymbol{x}_{\mathrm{f}, d}\right|}{\Delta x}\right]\right. \\
& \quad \text { if }\left|\boldsymbol{x}_{1}^{i}-\boldsymbol{x}_{\mathrm{f}, 1}\right|,\left|\boldsymbol{x}_{2}^{i}-\boldsymbol{x}_{\mathrm{f}, 2}\right|,\left|\boldsymbol{x}_{3}^{i}-\boldsymbol{x}_{\mathrm{f}, 3}\right|<\Delta x
\end{aligned}
$$$$
0 \text { otherwise. }
$$

$V_{\mathrm{g}}^{i}$ is the volume of grain $i . \Delta x^{3}$ is the fluid cell volume, and $\boldsymbol{x}_{\mathrm{f}}$ is the cell center position. $\Pi$ is the product operator. The average grain velocity at the cell center $(\overline{\boldsymbol{v}})$ is found using the same weighting function described above (Eq. 6). Additionally, large grains with velocity $\boldsymbol{v}^{i}$ contribute to the cell-average velocity with a greater magnitude:

$\overline{\boldsymbol{v}}\left(\boldsymbol{x}_{\mathrm{f}}\right)=\frac{\sum_{i \in N} s^{i} V_{\mathrm{g}}^{i} \boldsymbol{v}^{i}}{\sum_{i \in N} s^{i}}$.

The change in porosity is the main forcing the particles exert onto the fluid (Eq. 5). At time step $n$ it is estimated by central differences for second-order accuracy:

$\left[\frac{\partial \phi}{\partial t}\right]^{n} \approx \frac{\phi^{n+1}-\phi^{n-1}}{2 \Delta t}$.

The porosity at $n+1$ is found by estimating the upcoming particle positions from temporal integration of their current positions and velocities.

\subsubsection{Permeability}

Relations between grain size and hydraulic properties of sediments supported by empirical evidence (e.g., Hazen, 1911; Kozeny, 1927; Carman, 1937; Krumbein and Monk, 1943; Harleman et al., 1963; Schwartz and Zhang, 2003). The Kozeny-Carman estimation of permeability $k$ is commonly used and is of the form

$k=\frac{d^{2}}{180} \frac{\phi^{3}}{(1-\phi)^{2}}$,

where $d$ is the representative grain diameter. Due to constraints on the computational time step we are unable to simulate fine grain sizes with realistic elastic properties within a reasonable time frame. In order to give a first-order estimate of the deformational behavior of fine-grained sediments, we therefore use a modified version of the above relationship, where the permeability varies as a function of the porosity and a predefined permeability pre-factor $k_{\mathrm{c}}$ :

$k=k_{\mathrm{c}} \frac{\phi^{3}}{(1-\phi)^{2}}$. 
Using this approach we can simulate large particles with the hydrological properties of fine-grained materials, while retaining the effect of local porosity variations on the intrinsic permeability. We do note, however, that the dilative magnitude during deformation is likely different for clay materials due to their plate-like shape. This is because sediments with a considerable amount of arbitrarily oriented clay minerals are likely to compact during deformation as the clay particles align to accommodate shear strain.

\subsubsection{Particle-fluid interaction}

The dynamic coupling from the pore fluid to the solid particles acts through the particle-fluid force $\left(f_{\mathrm{i}}\right)$ in Eq. (1). Our implementation of this coupling follows the procedure outlined by Xu and Yu (1997), Feng and Yu (2004), and Zhou et al. (2010) (scheme 3). In a complete formulation, the interaction force between particles and the pore fluid consists of several components (e.g., Zhu et al., 2007).

The most well-known interaction force is the drag force, which is evident in Stokes' experiments of particle settling. This force is typically incorporated in particle-fluid models by semi-empirical relationships. It scales linearly with the relative velocity difference between particle and fluid and the particle-surface drag coefficient (Ergun, 1952; Wen and Yu, 1966; Gidaspow et al., 1992; Di Felice, 1994; Zhu et al., 2007).

The pressure-gradient force is another important fluidinteraction force (Anderson and Jackson, 1967; Zhu et al., 2007). It results when there is a difference in pressure across a surface and is well known from buoyancy. In liquids with hydrostatic pressure distributions the pressure grows linearly with depth as the weight of the overburden fluid increases. The resultant surface pressure on submerged body increases correspondingly with depth and causes a buoyant force upwards. In fluids without hydrostatic pressure distribution, the pressure-gradient force can be a highly variable vector field.

Several weaker interaction forces have been identified (Zhu et al., 2007), including forces due to particle rotation (Magnus force; Rubinow and Keller, 1961), lift forces on the particles caused by fluid velocity gradients (Saffman force; Saffman, 1965, 1968), and interaction forces caused by particle acceleration (virtual mass force; Odar and Hamilton, 1964; Odar, 1966).

Initial tests using a full Navier-Stokes solution for the fluid phase showed us that the pressure-gradient force was by far the dominant interaction force in our pseudo-static shear experiments. The drag force was the second-most important force but 2 orders of magnitude weaker than the pressuregradient force due to very slow fluid and particle flow. Since we neglect fluid inertia in our fluid description, we included only the pressure-gradient force. The fluid pressure in our model records the pressure difference from the hydrostatic pressure. For this reason we add a term to the pressuregradient force which describes the buoyancy of a fully sub-

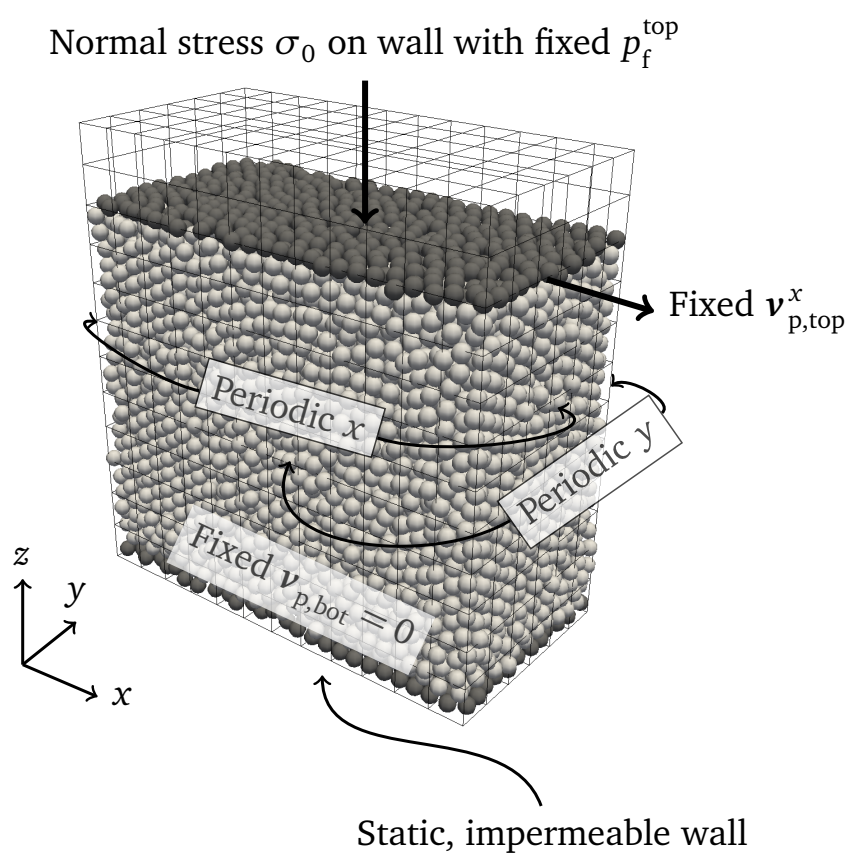

Figure 3. Experimental setup for the shear experiments. The fluid cells containing the mobile top wall are given a prescribed fixedpressure boundary condition ( $p_{\mathrm{f}}^{\text {top }}$, Dirichlet). The bottom boundary is impermeable (no flow, free slip Neumann). The fluid grid is extended upwards to allow for dilation and movement of the upper wall. The granular phase is compressed between a fixed wall at the bottom and a dynamic top wall, which exerts a normal stress $\left(\sigma_{0}\right)$ downwards. The material is sheared by moving the topmost particles parallel to the $x$ axis.

merged particle as the weight of the displaced fluid:

$\boldsymbol{f}_{\mathrm{i}}=-V_{\mathrm{g}} \nabla p_{\mathrm{f}}-\rho_{\mathrm{f}} V_{\mathrm{g}} \boldsymbol{g}$,

where $V_{\mathrm{g}}$ is the volume of the particle, $\rho_{\mathrm{f}}$ is the fluid density, and $\boldsymbol{g}$ is the vector of gravitational acceleration. The particlefluid interaction force is added to the sum of linear forces per particle (Eq. 1). The particle force is not added to the fluid pressure equation (Eq. 4) since fluid inertia is ignored. The fluid is instead forced by variations in porosity.

\subsection{Computational experiments}

The computational fluid dynamics algorithm is implemented in CUDA C (NVIDIA, 2013) in order to allow a direct integration with the GPU-based particle solver. The coupled particle-fluid code is free software (source code available at https://github.com/anders-dc/sphere), licensed under the GNU Public License v.3. The simulations were performed on a GNU/Linux system with a pair of NVIDIA Tesla K20c GPUs. The experimental results are visualized using ParaView (Henderson et al., 2007) and Matplotlib (Hunter, 2007).

The experimental setup is a rectangular volume (Fig. 3) where a fluid-saturated particle assemblage deforms due to 
Table 1. Parameter values used for the shear experiments.

\begin{tabular}{lll}
\hline Parameter & Symbol & Value \\
\hline Particle count & $N_{\mathrm{p}}$ & 9600 \\
Particle radius & $r$ & $0.01 \mathrm{~m}$ \\
Particle normal stiffness & $k_{\mathrm{n}}$ & $1.16 \times 10^{9} \mathrm{~N} \mathrm{~m}^{-1}$ \\
Particle tangential stiffness & $k_{\mathrm{t}}$ & $1.16 \times 10^{9} \mathrm{~N} \mathrm{~m}^{-1}$ \\
Particle friction coefficient & $\mu$ & 0.5 \\
Particle density & $\rho$ & $2600 \mathrm{~kg} \mathrm{~m}^{-3}$ \\
Fluid density & $\rho_{\mathrm{f}}$ & $1000 \mathrm{~kg} \mathrm{~m}^{-3}$ \\
Fluid dynamic viscosity & $\mu_{\mathrm{f}}$ & $1.797 \times 10^{-8}$ to $1.797 \times 10^{-6} \mathrm{Pas}$ \\
Fluid adiabatic compressibility & $\beta_{\mathrm{f}}$ & $1.426 \times 10^{-8} \mathrm{~Pa}^{-1}$ \\
Hydraulic permeability prefactor & $k_{\mathrm{c}}$ & {$\left[3.5 \times 10^{-15}, 3.5 \times 10^{-13}\right] \mathrm{m}^{2}$} \\
Normal stress & $\sigma_{0}$ & $20 \mathrm{kPa}^{2}$ \\
Top wall mass & $m_{\mathrm{w}}$ & $280 \mathrm{~kg}^{-2}$ \\
Gravitational acceleration & $g$ & $9.81 \mathrm{~m} \mathrm{~s}^{-2}$ \\
Spatial domain dimensions & $\boldsymbol{L}$ & {$[0.52,0.26,0.55] \mathrm{m}$} \\
Fluid grid size & $\boldsymbol{n}_{\mathrm{f}}$ & {$[12,6,12]$} \\
Shear velocity & $\boldsymbol{v}_{\mathrm{p}, \text { top }}^{x}$ & $2.32 \times 10^{-2} \mathrm{~m} \mathrm{~s}^{-1}$ \\
Inertia parameter value & $I$ & $1.7 \times 10^{-4}$ \\
Time step length & $\Delta t$ & $2.14 \times 10^{-7} \mathrm{~s}$ \\
Simulation length & $t_{\text {total }}$ & $20 \mathrm{~s}$ \\
\hline
\end{tabular}

forcings imposed at the outer boundaries. We deform the consolidated material by a constant-rate shearing motion in order to explore the macro-mechanical shear strength under different conditions.

To determine the effects of the pore water, we perform experiments with and without fluids, and for the experiments with fluids present, the permeability pre-factor $k_{\mathrm{c}}$ is varied to constrain the effect of the hydraulic conductivity and diffusivity on the overall deformation style. The low value used for $k_{\mathrm{c}}\left(3.5 \times 10^{-15} \mathrm{~m}^{2}\right)$ results in an intrinsic permeability of $k=1.9 \times 10^{-16} \mathrm{~m}^{2}$ for a porosity of 0.3 (Eq. 11). The highest value $\left(k_{\mathrm{c}}=3.5 \times 10^{-13} \mathrm{~m}^{2}\right)$ matches a permeability of $1.9 \times 10^{-14} \mathrm{~m}^{2}$. These two end-member permeabilities roughly correspond to what Iverson et al. (1997a) and Iverson et al. (1998) estimated for the clay-rich Two Rivers till and the clay-poor Storglaciären till, respectively.

The lower boundary is impermeable, and a fixed fluid pressure is specified for the top boundary. These boundary conditions imply that the simulated ice-bed interface is a relatively permeable zone with rapid diffusion of hydrological pressure, which is likely for subglacial beds with low permeability (e.g., Alley, 1989; Creyts and Schoof, 2009; Kyrke-Smith et al., 2014). In coarse-grained tills the subglacial till diffusivity may exceed the hydraulic diffusivity at the ice-bed interface, unless a network of linked cavities causes rapid diffusion of pore-water pressures here (e.g., Kamb, 1987). The lateral boundaries are periodic (wrap-around). When a particle moves outside the grid on the right side it immediately reappears on the left side. Likewise, particle pairs can be in mechanical contact although placed on opposite sides of the grid.
The particle size distribution is equidimensional, a stark contrast relative to subglacial tills which often display a fractal size distribution (e.g., Hooke and Iverson, 1995). Fractal size distributions minimize internal stress heterogeneities (Hooke and Iverson, 1995; Iverson et al., 1996), but, in the absence of grain crushing, an assemblage with a wide particle size distribution dilates from a consolidated state with the same magnitude as assemblages with a narrow particle size distribution (Morgan, 1999) and displays the same frictional strength (Morgan, 1999; Mair et al., 2002; Mair and Hazzard, 2007). The comparable dilation magnitude justifies the computationally efficient narrow particle size distribution used here. However, as previously noted, shear zones in clayrich materials can compact during shear due to preferential parallel alignment, which is not possible to capture with the methodology presented here.

The simulated particle size falls in the gravel category of grain size (Table 1). The large size allows us to perform the temporal integration with larger time steps (Radjaï and Dubois, 2011; Damsgaard et al., 2013). The frictional force between two bodies is independent of their size (Amontons' second law) but is proportional to the normal force on the contact interface (Mitchell and Soga, 2005), as reflected in the contact law in the discrete element method (Eq. 3). We prescribe the normal forcing at the boundary as a normal stress, which implies that the normal force exerted onto a particle assemblage at the boundaries scales with domain size. For a number of total particles in a given packing configuration the ratio between particle size and inter-particle force is constant, which causes the shear strength to be independent of simulated particle size. This scale independence is 

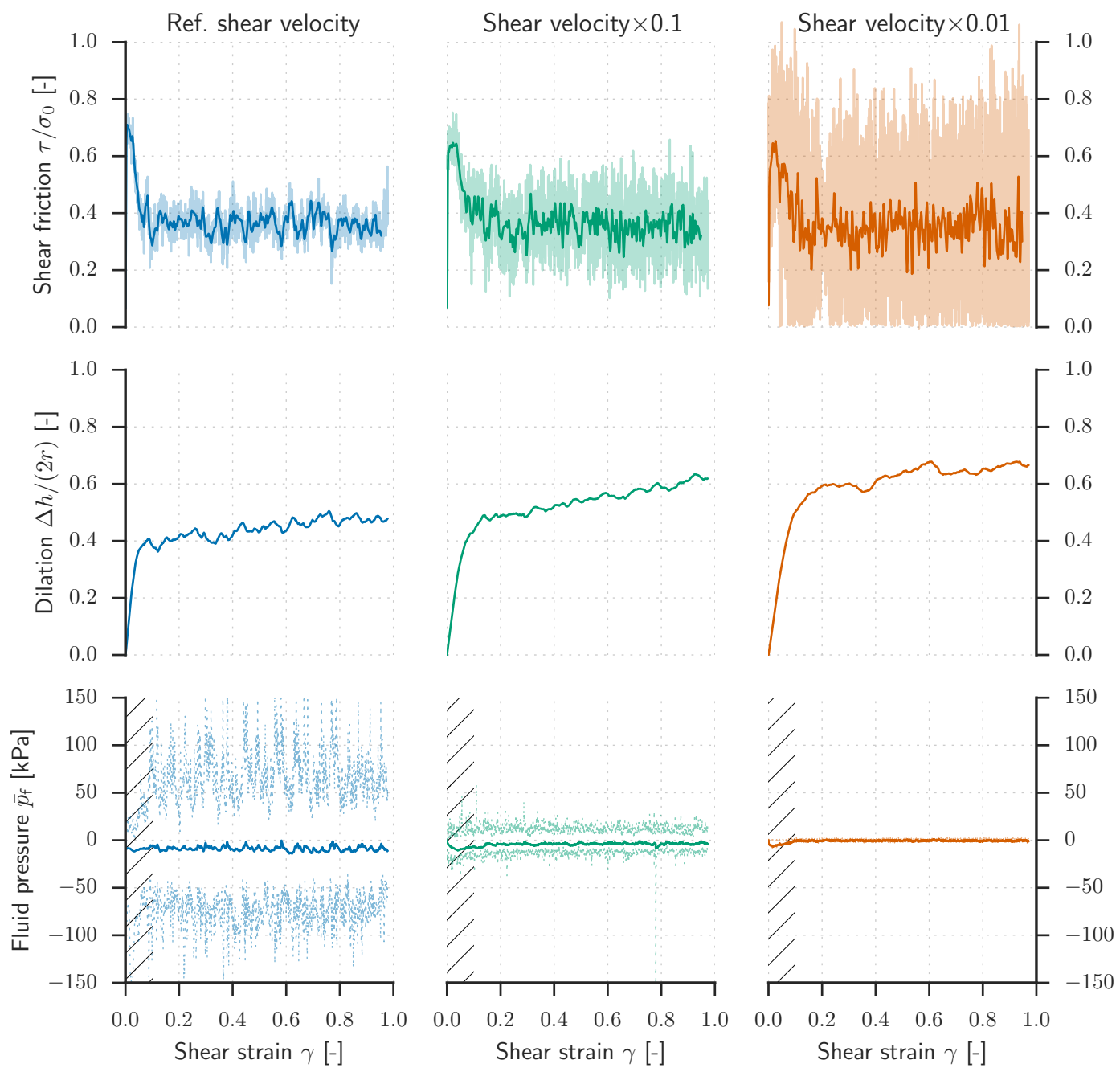

Figure 4. Shear experiments with different shearing rates. (Top) Unsmoothed and smoothed shear friction values, (center) dilation in number of grain diameters, and (bottom) minimum, mean, and maximum fluid pressures. The permeability prefactor value is $k_{\mathrm{c}}=3.5 \times 10^{-15} \mathrm{~m}^{2}$. The shear friction values (top) are smoothed with a moving Hanning window function to approximate the strength of larger particle assemblages. The material peak friction increases with strain rate due to reductions of internal fluid pressure. This strengthening is taking place when the dilation rate exceeds the dissipation rate of the fluid. The diagonal hatched pattern marks the earliest state of shear characterized by rapid dilation.

verified in laboratory experiments, where the granular shear strength of non-clay materials is known to be mainly governed by grain shape and surface roughness instead of grain size (Schellart, 2000; Mitchell and Soga, 2005).

\subsubsection{Experiment preparation and procedure}

The particles are initially positioned in a dry, tall volume, from where gravity allows them to settle into a dense state at the bottom of the bounding box. The particle assemblage is then consolidated by moving the top wall downwards until the desired level of consolidation stress is reached for an extended amount of time. The same top wall is thereafter used to shear the material in a fluid-saturated state (Fig. 3).
For the shear experiments, the uppermost particles are forced to move with the top wall at a prescribed horizontal velocity (Fig. 3). The particles just above the bottom wall are prescribed to be neither moving or rotating. The physical size of the domain is $0.52 \mathrm{~m}$ long in the direction of shear $(x)$, $0.26 \mathrm{~m}$ in the transverse horizontal direction $(y)$, and $0.55 \mathrm{~m}$ tall $(z)$. We use the exact same material for all shear experiments, allowing for perfect reproducibility and effectively removing inter-experimental variability caused by differences in grain packing. The micromechanical properties and geometrical values used are listed in Table 1. 


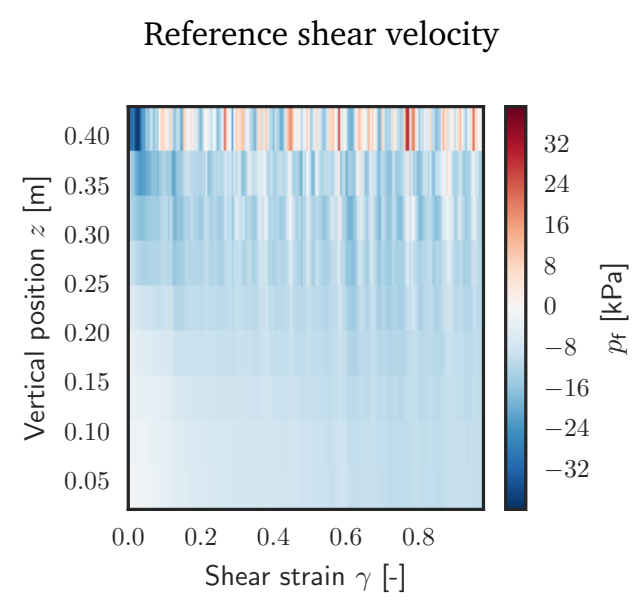

Reference shear velocity $\times 0.1$

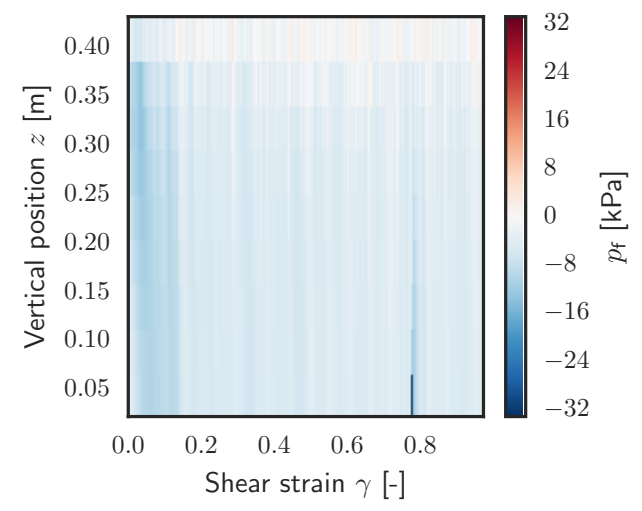

Reference shear velocity $\times 0.01$

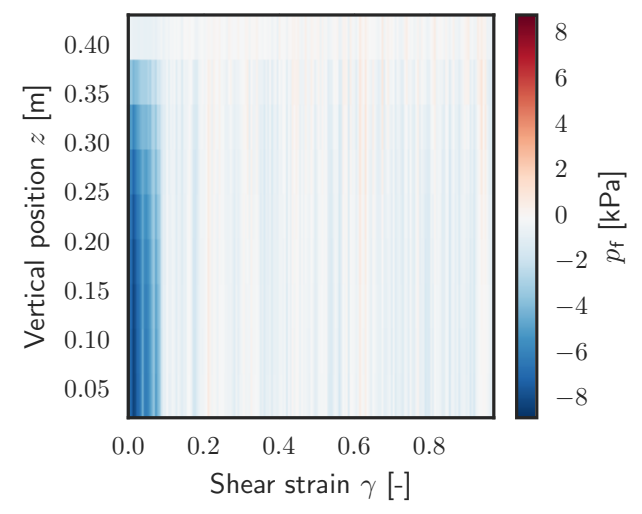

Figure 5. Temporal evolution ( $x$ axis) of the horizontally averaged fluid pressures (color bar) as a function of the height above the base ( $y$ axis). At fast shear rates (top) there are large internal pressure decreases and slow recovery due to a large dilation rate and an insufficient pressure dissipation. When the shearing velocity is decreased (middle) and (bottom) the dissipation rate becomes increasingly capable of keeping internal pressures close to the hydrostatic pressure $(0 \mathrm{kPa})$.

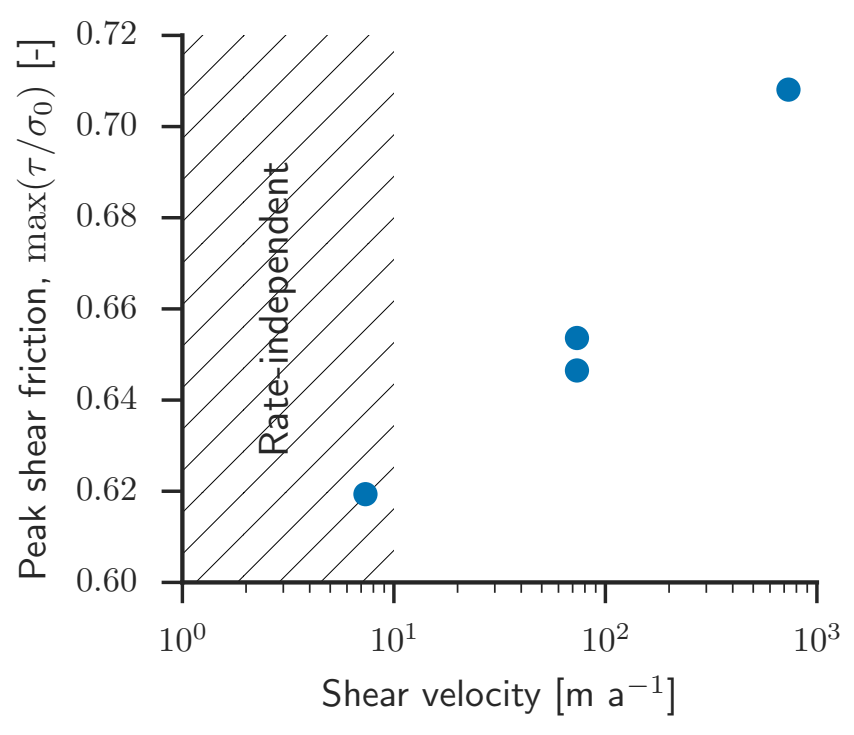

Figure 6. Peak frictional strength before the critical state of the lowpermeability granular bed $\left(k_{\mathrm{c}}=3.5 \times 10^{-15} \mathrm{~m}^{2}\right)$ at different shear velocities. The frictional strength is constant and rate independent at velocities lower than $10^{1} \mathrm{ma}^{-1}$ as pore-pressure diffusion rates far exceed rates in volumetric change.

\subsubsection{Scaling of the shear velocity}

The heavy computational requirements of the discrete element method necessitates upscaling of the shearing velocity in order to reach a considerable shear strain within a manageable length of time. Temporal upscaling does not influence the mechanical behavior of dry granular materials, as long as the velocity is below a certain limiting velocity (GDR-MiDi, 2004; Damsgaard et al., 2013; Gu et al., 2014). The shearing velocity used here $\left(2.32 \times 10^{-2} \mathrm{~m} \mathrm{~s}^{-1}\right)$, although roughly 3 orders of magnitude greater than the velocities observed in subglacial environments (e.g., $316 \mathrm{ma}^{-1}=10^{-5} \mathrm{~m} \mathrm{~s}^{-1}$ ), guarantees quasi-static, rate-independent deformation in the granular phase, identical to the behavior at lower strain rates. The particle inertia parameter, $I$, quantifies the influence of grain inertia in dry granular materials (GDR-MiDi, 2004). Values of $I$ below $10^{-3}$ correspond to pseudo-static and rateindependent shear deformation in dry granular materials. $I$ has a value of $1.7 \times 10^{-4}$ in the shear experiments of this study.

The fluid phase needs separate treatment in order to correctly resolve slow shear behavior at faster shearing velocities. This behavior is achieved by linearly scaling the fluid dynamic viscosity with the relationship between actual shearing velocity and the reference glacial sliding velocity. By decreasing the viscosity, the fluid is allowed to more quickly adjust to external and internal forcings. The velocity scaling adjusts the time-dependent parameters of hydraulic conductivity and diffusivity correctly. The intrinsic permeability $k$ is time independent, and the values produced here 

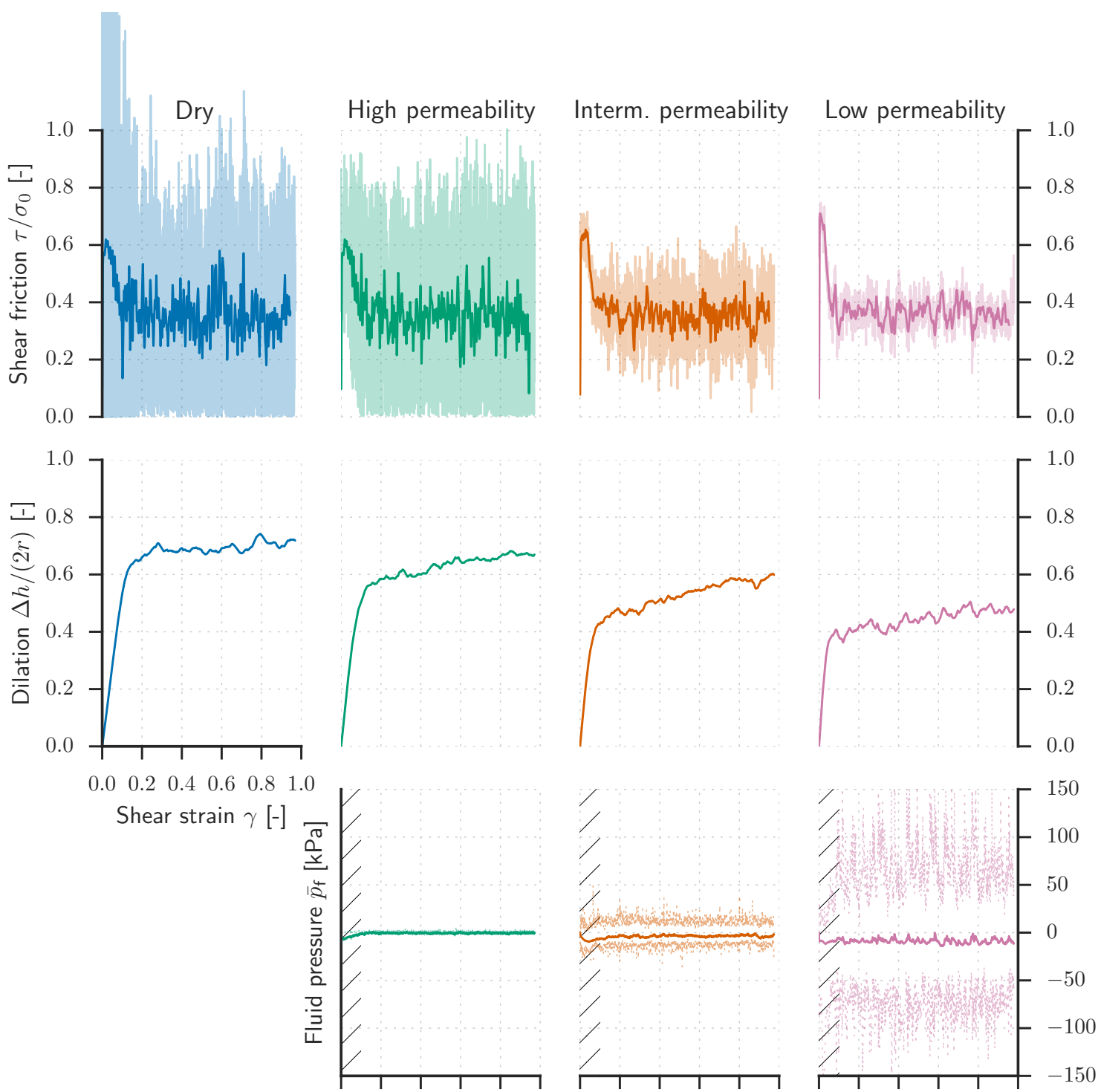

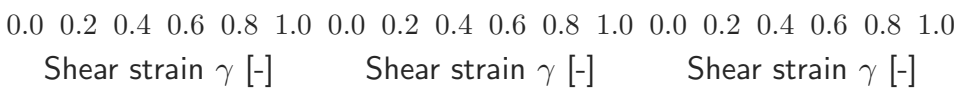

Figure 7. (Top) Shear strength, (center) dilation in number of grain diameters, and (bottom) minimum, mean, and maximum fluid pressures in shear experiments with different permeability properties.

are directly comparable with real geological materials. The fluid viscosity is scaled to a lower value of $1.797 \times 10^{-6} \mathrm{~Pa} \mathrm{~s}$, consistent with the scaling factor used for the shearing velocity. We test the influence of shearing rate by varying this parameter.

\section{Results}

First we investigate the strain-rate dependence of the sediment strength and dilation by shearing a relatively impermeable sediment $\left(k_{\mathrm{c}}=3.5 \times 10^{-15} \mathrm{~m}^{2}\right)$ at different shear velocities. The shear velocity directly influences the magnitude of the peak shear strength, dilation, and internal fluid pressure (Figs. 4 and 5).

At the reference shearing velocity the peak shear frictional strength is 0.71 , which corresponds to a shear stress of $14 \mathrm{kPa}$ at an effective stress of $20 \mathrm{kPa}$ (Figs. 4, top left, and 6). When sheared 100 times slower, the peak shear friction has decreased to 0.62 , corresponding to a shear stress of $12 \mathrm{kPa}$ (Figs. 4, top right, and 6). The peak values are measured during the transition from the dense and consolidated pre-failure state to the critical state where a shear zone is fully established. This transition is characterized by rapid dilation due to porosity increases in the shear zone 

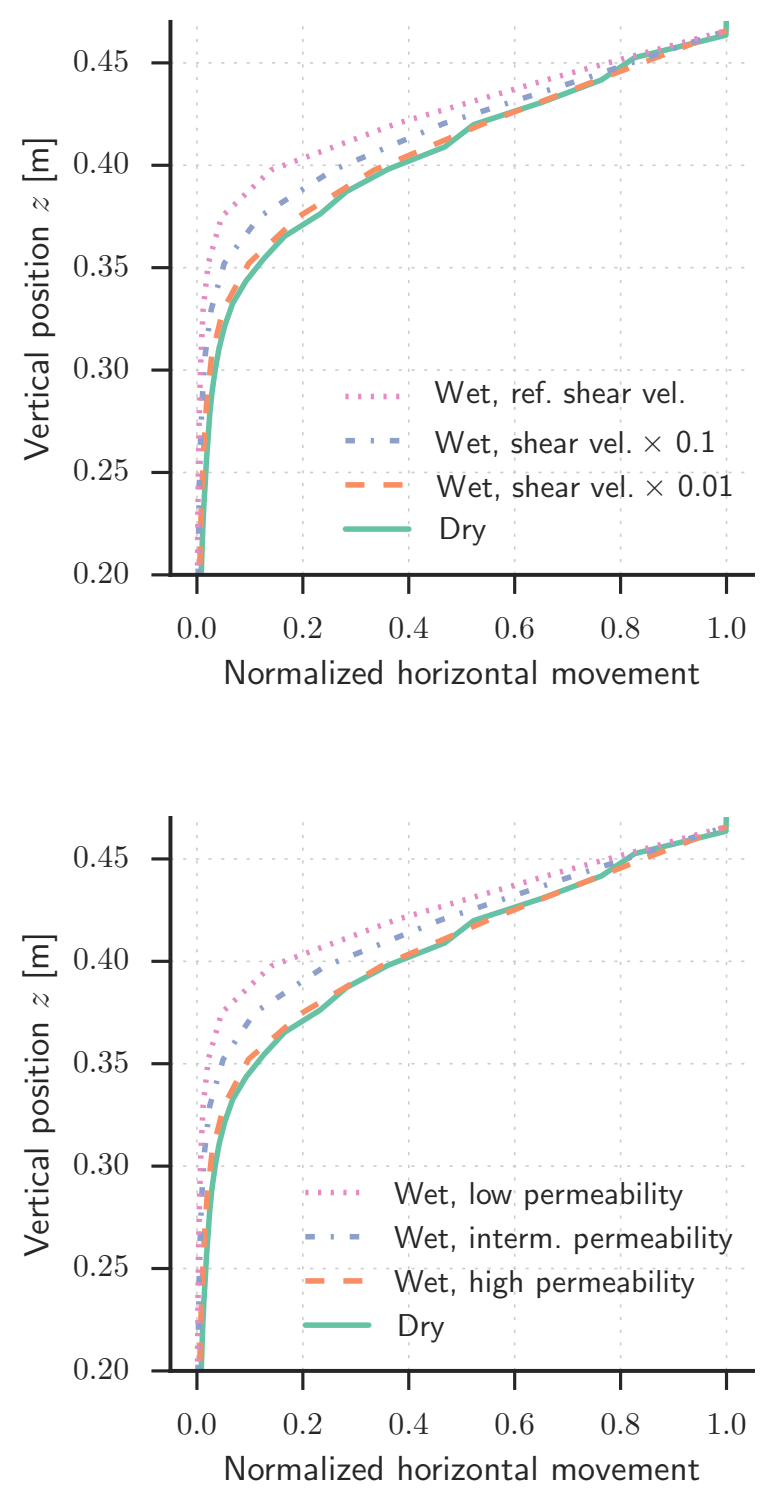

Figure 8. Horizontal particle displacement with depth (shear strain profiles) for the dry and fluid-saturated shear experiments. Top: displacement profiles from experiments with different shear velocities. Bottom: displacement profiles from experiments with different permeabilities.

(Fig. 4, middle). During fast shearing velocities the volumetric change outpaces the diffusion of fluid pressure, causing the internal pore-water pressure in the shear zone to decline (Figs. 4, bottom, and 5). Dilatant hardening causes the peak shear strength to increase at large shear velocities (Fig. 6), while the strength reduces to values corresponding to the rate-independent granular strength for lower velocities.

In this model framework, adjusting the hydraulic permeability of the same coarse sediment leads to similar conditional strengthening as shearing the sediment at different rates (Fig. 7). Without fluids (the dry experiment), the peak shear friction (Fig. 7, left) is relatively low and is domi- nated by high-frequency fluctuations. The fluid-saturated experiment with the relatively high permeability $\left(k_{\mathrm{c}}=3.5 \times\right.$ $10^{-13} \mathrm{~m}^{2}$ ) has similar shear strength, but the high-frequency oscillations in shear friction are reduced by the fluid presence. The dilation is similar to the dry experiment but with slightly decreased magnitude. The mean fluid pressure deviation from hydrostatic values (Fig. 7, bottom left) is close to 0 . The low-permeability experiment (Fig. 7, right) is characterized by the largest initial peak strength and lowest magnitude of dilation. Compared to the other experiments, the dilation reaches its maximum values at lower shear strain. The fluid pressure decreases almost instantaneously at first, whereafter it equilibrates towards the hydrostatic value $(0 \mathrm{~Pa})$.

At constant shearing rate with different permeabilities (Fig. 8, top) or at variable shearing rates with constant permeability (Fig. 8, bottom), we observe that pore-water dynamics have a significant effect on the distribution of strain. The effects of the fluid are visible at different depths within the deforming material (Figs. 9 and 10). The deformation is pervasive with depth for the relatively permeable experiment (Fig. 9 top), and the fluid pressures deviate only slightly from the hydrostatic values. The relatively small pressure gradients cause only weak fluid forces on the particles in this experiment. Contrasting these results, deformation in the impermeable experiment is primarily governed by shallow deformation beneath the top wall (Figs. 9 and 10, bottom).

Differences in hydraulic permeability influence the dynamics of the fluid over time, as illustrated in Fig. 11. The fluid pressures in the permeable material (top) are initially predominantly negative, reflecting the increasing dilation (Fig. 7, middle). In the critical state (after a shear strain value of 0.1 ), the fluid pressures fluctuate around the hydrostatic value $(0 \mathrm{~Pa})$.

\section{Discussion}

\subsection{Strain-rate dependency}

Several studies have highlighted the importance of feedbacks between the solid and fluid phases during granular deformation (e.g., Iverson et al., 1994, 1997b, 1998; Pailha et al., 2008; Iverson, 2010; Rondon et al., 2011; Mutabaruka et al., 2014). A shear-rate dependence in a grain-fluid mixture can only originate from the fluid phase, since dry granular materials deform rate-independently under pseudo-static shear deformation (GDR-MiDi, 2004; Damsgaard et al., 2013). Rate dependence emerges, however, as soon as the flow of viscous pore fluids starts to influence the solid phase.

Water has a relatively low viscosity, which implies that the shear stress required to deform the fluid phase alone is extremely low. However, the fluid phase influences the bulk rheology if diffusion of fluid pressures is limited relative to volumetric forcing rates, as in a rapidly deforming but relatively impermeable porous material. The coupled particle- 


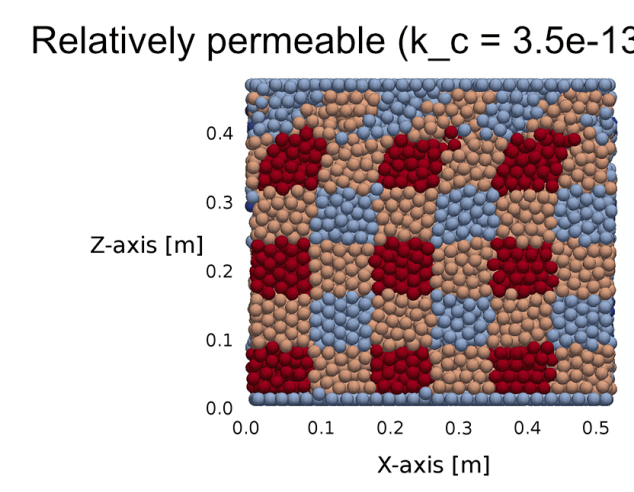

Vertical fluid pressure force $(\mathrm{N})$
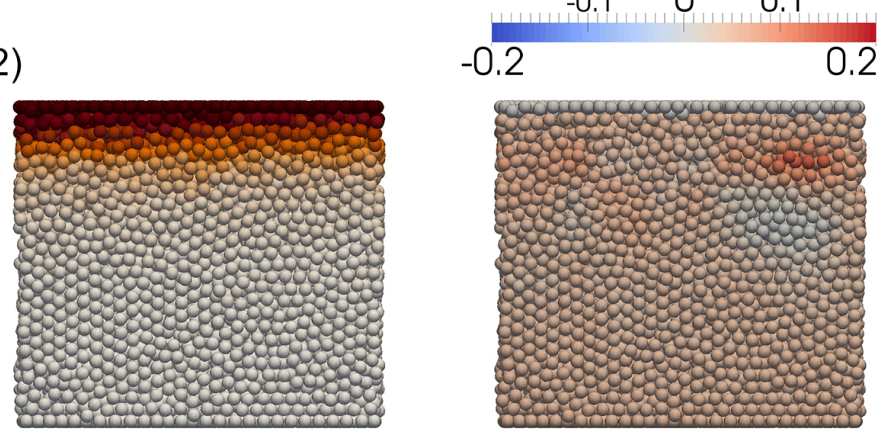

Horizontal displacement (m)
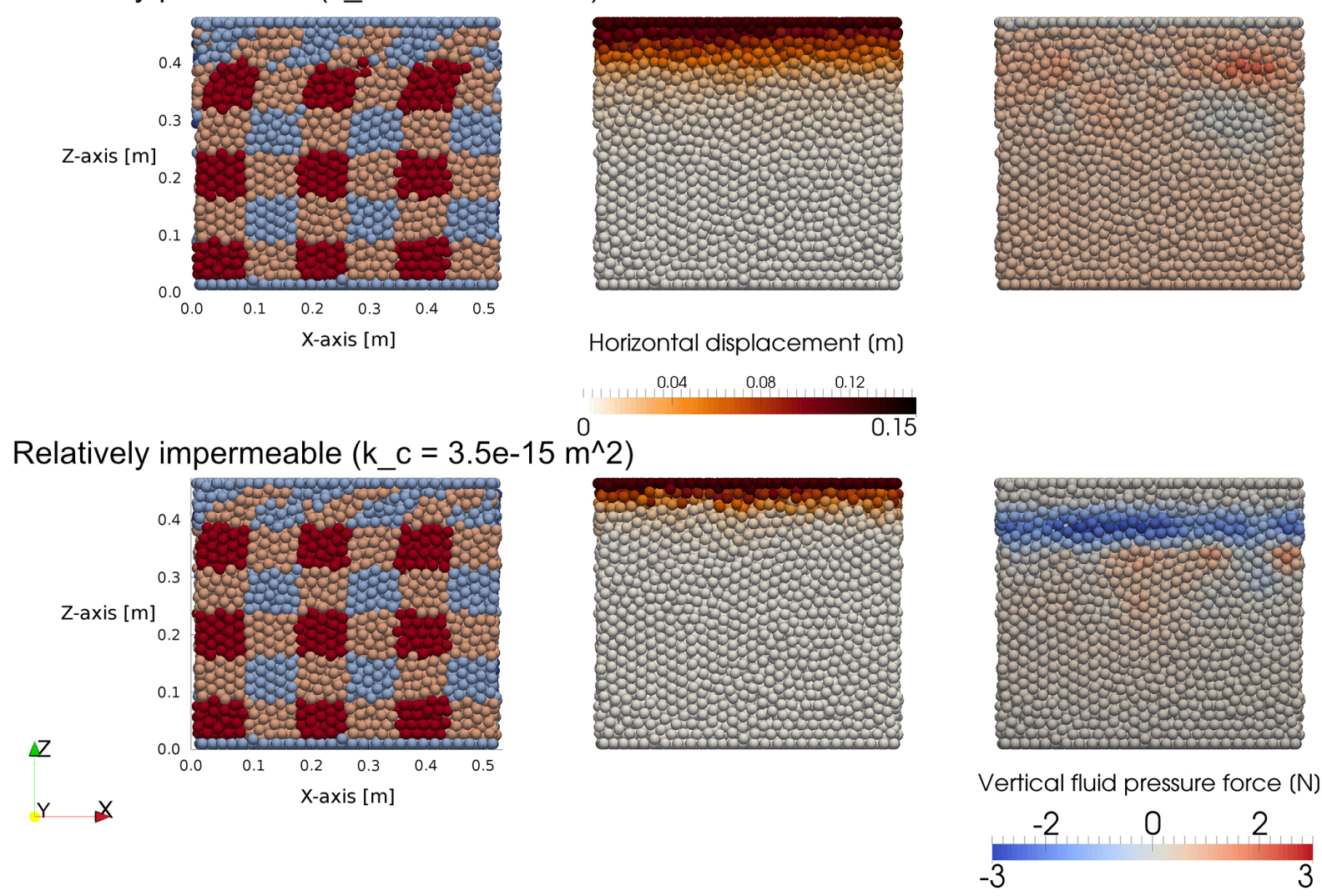

Figure 9. Particle displacement and fluid forces for different permeabilities at a shear strain of 0.25 . (Left) Particles colored by their original position; (center) particles colored by their displacement along the $x$ axis; (right) vertical $(z)$ forces from the fluid onto the particles. In the permeable material (top), the internal volumetric changes are accommodated by porous (Darcian) flow. This keeps the fluid pressures close to hydrostatic values and causes deep deformation (top center). In materials which are impermeable (bottom), the volumetric changes cause drastic pore-pressure reductions, effectively strengthening the material (bottom right) and focusing deformation at the top (bottom left and center).

fluid interactions cause the material to respond as a low-pass filter when forced with changes in volume and porosity. The reequilibration of pressure anomalies depends on the volumetric strain rate, water viscosity, and material permeability. Any forcing that affects local porosity causes the material to respond in part like a viscous dashpot due to internal fluid flow.

The pore-fluid viscosity likely increases if suspended clayparticles or ice crystals are present. The exact rheology of such mixtures may very well be non-Newtonian, and we have therefore not included such effects in this study.

\subsection{Dilatant hardening: effects on sediment strength and deformation depth}

Transient porosity changes take place when granular materials deform before attaining the critical state (e.g., Reynolds,
1885; Mead, 1925; Schofield and Wroth, 1968; Iverson et al., 2000). These changes can cause deviation from the hydrostatic pressure distribution, which affects the magnitude of the local effective normal stress. Considering the MohrCoulomb constitutive relation for till rheology, a reduction in pore-water pressure increases the effective stress, which in turn strengthens the material in the shear zone (Fig. 12) (e.g., Iverson et al., 1997b, 1998; Moore and Iverson, 2002; Iverson, 2010). In our results we obtain insight into the micromechanical mechanisms of strengthening without explicitly specifying Mohr-Coulomb constitutive behavior. Deviations from the hydrostatic pressure distribution cause pressuregradient forces, which during dilation resist the development by pushing the grains together towards the low pressure of the shear zone (Fig. 13). The tangential strength of interparticle contacts in the DEM is determined by Coulomb friction (Eq. 3), which implies a linear correlation between con- 


\section{High permeability $\left(k_{c}=3.5 \times 10^{-13} \mathrm{~m}^{2}\right)$}
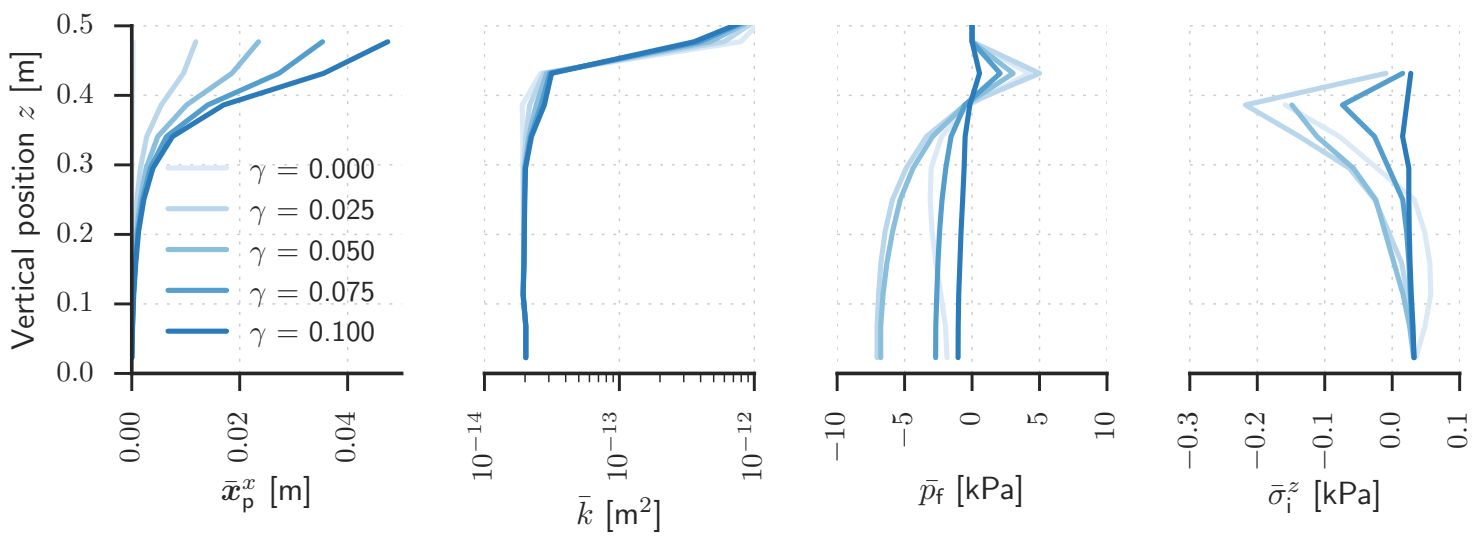

Intermediate permeability $\left(k_{c}=3.5 \times 10^{-14} \mathrm{~m}^{2}\right)$
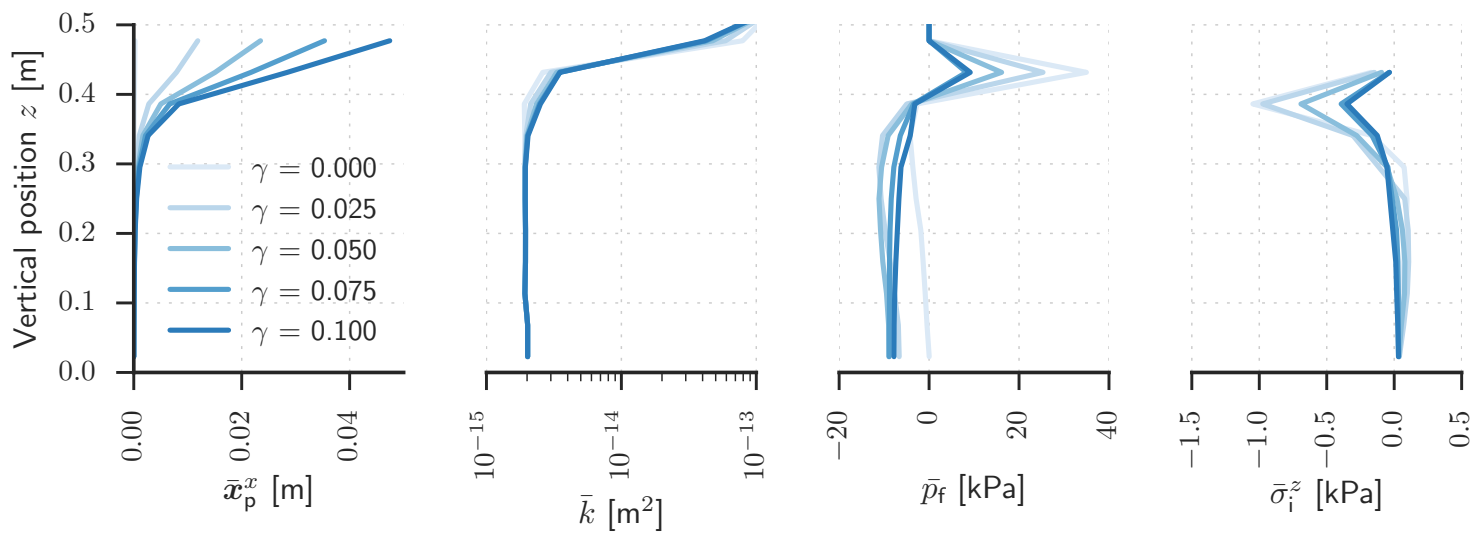

Low permeability $\left(k_{c}=3.5 \times 10^{-15} \mathrm{~m}^{2}\right)$
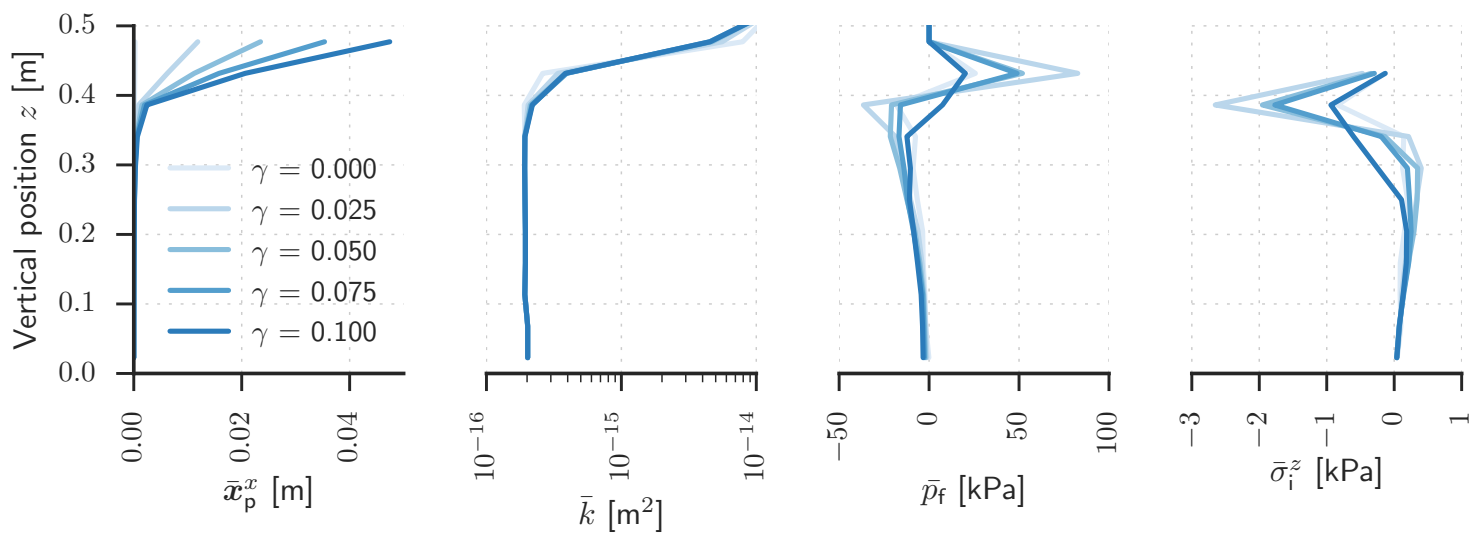

Figure 10. Horizontally averaged fluid and particle behavior with progressive shear strain. (left) Vertical particle displacement, (center left) mean permeability, (center right) mean fluid pressure, and (right) vertical component of the mean fluid stress, calculated as $\boldsymbol{f}_{\mathrm{i}}^{i} / A^{i}$, where $f_{\mathrm{i}}^{i}$ is the fluid pressure force on particle $i$ from Eq. (12) and $A^{i}$ is its surface area. Note that the limits of the horizontal axes differ between the experiments. 


$$
\text { Relatively permeable }\left(k_{c}=3.5 \times 10^{-13} \mathrm{~m}^{2}\right)
$$

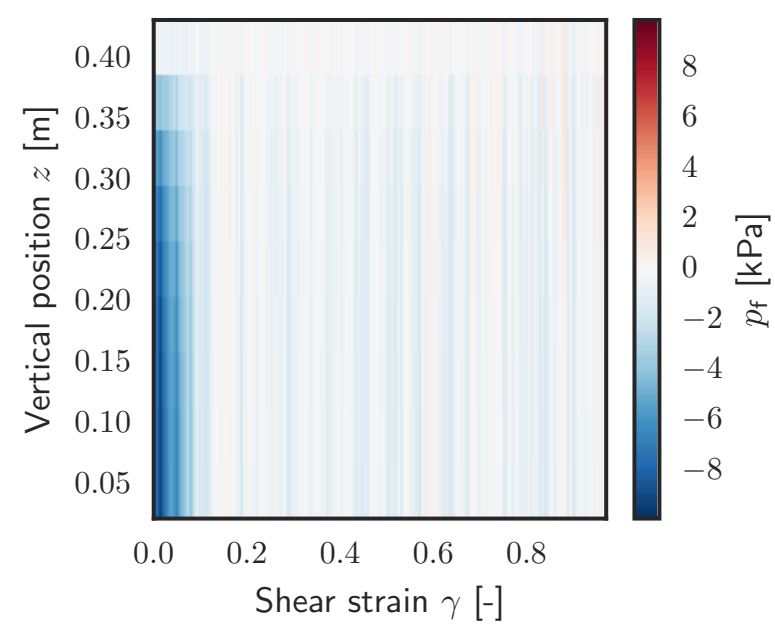

Relatively impermeable $\left(k_{c}=3.5 \times 10^{-15} \mathrm{~m}^{2}\right)$

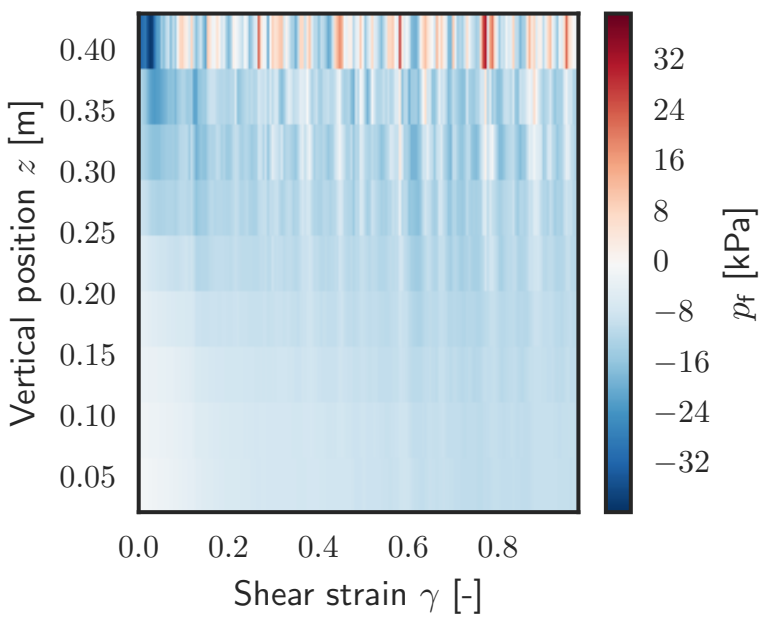

Figure 11. Temporal evolution ( $x$ axis) of horizontally averaged fluid pressures ( $y$ axis). The permeable material (top) is able to quickly respond to internal volumetric changes, which are shortlived and of small magnitude. The low-permeability material (bottom) is dominated by large pressure reductions and relatively slow relaxation.

tact normal force and tangential contact strength. Heavily loaded particle contacts are thus less likely to slip, and chains of particles with strong contacts cause increased resistance to deformation (Damsgaard et al., 2013). The fluid force on the particles strengthens the inter-particle contacts and increases the shear friction until hydrostatic pressure conditions are reestablished.

The dilatant hardening causes a shallower deformational profile in these experiments (Figs. 12, 9 left, and 8). The hardening vanishes at higher strains as the hydrostatic pres-

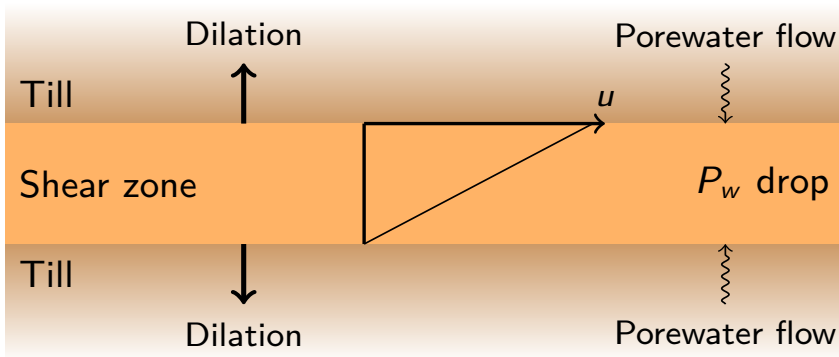

Figure 12. Particle-fluid interaction during deformation of a consolidated sediment (after Iverson et al., 1998).

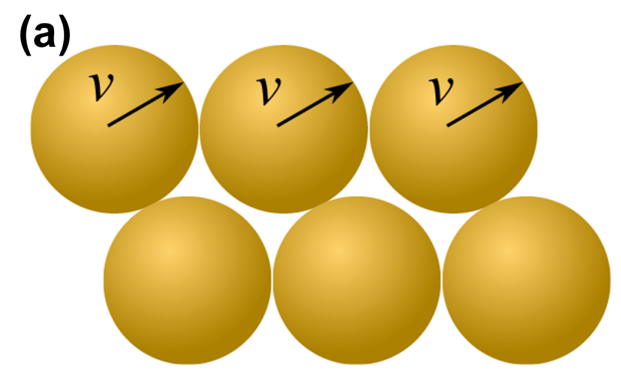

(b)

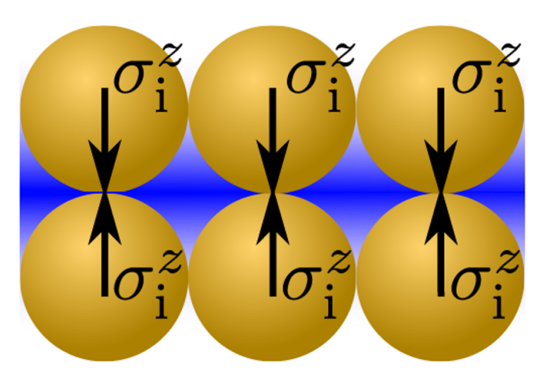

Figure 13. Micromechanical cause of dilatant hardening. A consolidated sediment (top) is deformed with a vertical gradient in velocity. The grains are forced past each other in order to accommodate the shear strain. The deformation causes dilation, which increases porosity locally and decreases fluid pressure (bottom). The gradient in fluid pressure pulls particles together (Eq. 12), which increases the load on inter-particle contacts. The larger inter-particle normal stress increases the shear strength of the contact (Eq. 3) resulting in a stronger sediment.

sure distribution is recovered at all depths of the material, and the deformational profiles progressively deepen until they match the dry experiment at higher shear-strain values $(\gtrsim 2)$. This progressive widening of the shear zone causes dilation to slowly increase while shear strength only displays very slight decrease (Figs. 4 and 7). The shallow deformation at low strains is consistent with the laboratory results by Iverson et al. (1997a), where the shear zone in the coarse-grained Storglaciären till in all cases was wider than the shear zone of the fine-grained Two Rivers till. The velocity profile of 
the shear zone determines the material flux. A shallower deformation depth and a transiently lower subglacial sediment transport rate is thus to be expected from subglacial shearing of compacted, low-permeable sediments, relative to permeable counterparts. These results are consistent with observations of very shallow deformation in subglacial tills with a relatively low permeability (Engelhardt and Kamb, 1998; Piotrowski et al., 2004), although shallow deformation is also consistent with fine grain sizes (Tulaczyk, 1999), low effective stresses (Damsgaard et al., 2013), and rate-weakening ploughing at the ice-till interface (Thomason and Iverson, 2008).

Owing to the granularity of the material, the dilation displays small fluctuations around the critical-state value. The small volumetric oscillations create new fluid-pressure deviations from the hydrostatic value, which alternately slightly weaken or strengthen the sediment (Fig. 7, top). In cases where the shear stress is close to the sediment shear strength, the hardening may be sufficient to stabilize patches of the bed (Piotrowski, 1987), or the weakening may trigger slip (Goren et al., 2011).

Shear deformation can cause compaction instead of dilation if the material porosity exceeds the critical-state porosity, if elongated grains rotate into a more compact arrangement with high fabric strength, or if relatively soft granular components such as aggregates disintegrate. Compactioninduced weakening is a primary mechanism for debris-flow mobilization in landslides, as demonstrated experimentally at small scales (Iverson et al., 2010) and at field scales (Iverson et al., 2000). The granular model applied here is not able to reproduce the shear-induced compaction that, e.g., clayrich materials can display during early shear due to clayfabric development (e.g., Dewhurst et al., 1996). Compaction causes increased pore-water pressure in the shear zone in cases where the volumetric change exceeds the timescale of pore-water pressure diffusion. Some of the effective normal stress on the shear zone is consequentially reduced, which in turn decreases the material strength. The reduction of strength due to compaction is rate dependent like the dilative hardening.

Our results confirm that the interplay between the solid and fluid phases can influence the sediment strength in a transient manner (e.g., Moore and Iverson, 2002; Iverson et al., 1998; Iverson, 2010). Pore-water pressures decrease during deformation, and shear strength increases until deformation ceases or the critical state is reached. Once the local and regional hydraulic system recovers from the pore-pressure reduction, the sediment strength is once again reduced and a new deformation phase may be initiated. The magnitude of strengthening is dictated by consolidation at times between slip events as well as the ability of the subglacial hydrological system to accommodate reductions in pressure at the icebed interface.

A variable shear strength of the till influences ice flow when the basal shear stress is in the range of till strength variability. Since surface slopes of ice streams are low, driving stresses tend to be low as well. Inferred values of driving stresses at the Northeast Greenland ice stream (Joughin et al., 2001), Whillans Ice Stream and ice plain (Engelhardt and Kamb, 1998), and Pine Island Glacier (Thomas et al., 2004) lie within the range of 2 to $23 \mathrm{kPa}$ (Alley and Whillans, 1991; Cuffey and Paterson, 2010) and are thus potentially sensitive to the variability in till strength. If the glacier moves with variable velocities in a stick-slip or surging manner, periods of stagnation may consolidate and strengthen the sediment, in effect delaying the following slip event (Iverson, 2010). Future studies will focus on investigating the mechanical consequences of transiently variable stresses, caused by changes in pore-water pressure or shear stress.

\section{Conclusions}

We numerically simulate a two-way coupled particle-fluid mixture under pseudo-static shear deformation and confirm results on transient strengthening from previous physical experiments (e.g., Moore and Iverson, 2002) and calculations (e.g., Iverson et al., 1998).

The grains are simulated individually by the discrete element method, while the fluid phase is treated as a compressible and slowly flowing fluid adhering to Darcy's law. The fluid influences the particles through local deviations from the hydrostatic pressure distribution. Due to the extremely low viscosity of water, the deformational behavior of dense granular material is governed by inter-grain contact mechanics. The porosity of a granular packing evolves asymptotically towards a critical-state value with increasing shear strain. Changes in porosity cause deviations from the hydrostatic pressure if the rate of porosity change exceeds the rate of pressure diffusion. The rate of pressure diffusion is governed by the fluid viscosity, the local porosity, and the hydraulic permeability. Low fluid pressures developing due to sediment dilation increase the frictional strength of intergrain contacts by increasing the loading between grain pairs. The magnitude of the strengthening effect is rate dependent and increases with shear velocity and decreases with increasing hydraulic permeability. The rheology is plastic but ratedependent dilative strengthening can contribute to the material strength during early stages of fast deformation. If the till is very porous or the deformation is accompanied by strong fabric development or grain crushing, compaction in the shear zone is expected to weaken the sediment, causing a rate weakening with increased shear rate until the excess pressures are reduced by hydraulic diffusion.

We furthermore show that for fast shear velocities permeable sediments are only weakly influenced by the fluid phase, resulting in little shear strengthening and a deep decimeter-scale deformation dictated by the normal stress and grain sizes. Impermeable and consolidated sediments display slight dilatant strengthening at high shear velocity. 
The strengthening causes deformation to focus at the ice-bed interface if pore-water pressures are higher there. The resultant depth of deformation is on the millimeter-to-centimeter scale. Actively deforming patches in the subglacial mosaic of deforming and stable spots act as sinks for meltwater. Additionally, sediment dilation can cause substantial thinning of a water film at the ice-bed interface. If the subglacial shearing movement halts, the sediment gradually weakens as the fluid pressure readjusts to the hydrostatic value. These temporal changes in sediment strength may explain observed variability in glacier movement.

Acknowledgements. Anders Damsgaard benefited from discussions with Jean-Yves Delenne, Hans Petter Langtangen, Kenni Dinesen Petersen, Keld Rømer Rasmussen, Liran Goren, and Jenny Suckale during model development and application. We thank Neal R. Iverson and an anonymous referee for constructive comments which improved the manuscript and Chris R. Stokes for handling the editorial process. This research was funded by the Danish Council for Independent Research under the Sapere Aude programme.

Edited by: C. R. Stokes

\section{References}

Alley, R. B.: Water-pressure coupling of sliding and bed deformation: I. Water system, J. Glaciol., 35, 108-118, 1989.

Alley, R. B.: In search of ice-stream sticky spots, J. Glaciol., 39, 447-454, 1993.

Alley, R. B. and Whillans, I. M.: Changes in the West Antarctic ice sheet, Science, 254, 959-963, 1991.

Alley, R. B., Blankenship, D. D., Rooney, S. T., and Bentley, C. R.: Till beneath ice stream B 4. A coupled ice-till flow model, J. Geophys. Res., 92, 8931-8940, 1987.

Anderson, T. B. and Jackson, R.: A fluid mechanical description of fluidized beds, Ind. Eng. Chem., 6, 527-539, 1967.

Bindschadler, R., Bamber, J., and Anandakrishnan, S.: Onset of streaming flow in the siple coast region, West Antarctica, in: The West Antarctic Ice Sheet: Behavior and Environment, American Geophysical Union, John Wiley \& Sons, Ltd, Hoboken, New Jersey, USA, 123-136, 2001.

Booth, A. M., Hurley, R., Lamb, M. P., and Andrade, J. E.: Force chains as the link between particle and bulk friction angles in granular material, Geophys. Res. Lett., 41, doi:10.1002/2014GL061981, 2014.

Bougamont, M., Price, S., Christoffersen, P., and Payne, A. J.: Dynamic patterns of ice stream flow in a 3-D higher-order ice sheet model with plastic bed and simplified hydrology, J. Geophys. Res.-Earth, 116, F04018, doi:10.1029/2011JF002025, 2011.

Boulton, G. S. and Hindmarsh, R. C. A.: Sediment deformation beneath glaciers: rheology and geological consequences, J. Geophys. Res., 92, 9059-9082, 1987.

Carman, P. C.: Fluid flow through granular beds, Trans. Inst. Chem. Eng., 15, 150-166, 1937.
Catalano, E., Chareyre, B., and Barthélémy, E.: Pore-scale modeling of fluid-particles interaction and emerging poromechanical effects, Int. J. Numer. Anal. Met., 38, 51-71, 2014.

Clark, C. D., Tulaczyk, S. M., Stokes, C. R., and Canals, M.: A groove-ploughing theory for the production of mega-scale glacial lineations, and implications for ice-stream mechanics, J. Glaciol., 49, 240-256, 2003.

Clarke, G. K. C.: Subglacial processes, Annu. Rev. Earth Pl. Sc., 33, 247-276, 2005.

Courant, R., Friedrichs, K., and Lewy, H.: On the partial difference equations of mathematical physics, IBM J. Res. Dev., 11, 215234, 1967.

Creyts, T. T. and Schoof, C. G.: Drainage through subglacial water sheets, J. Geophys. Res.-Earth, 114, 2156-2202, 2009.

Cuffey, K. M. and Paterson, W. S. B.: The Physics of Glaciers, Elsevier, Amsterdam, Netherlands, 4, 693, 2010.

Cundall, P. A. and Strack, O. D. L.: A discrete numerical model for granular assemblies, Geotechnique, 29, 47-65, 1979.

Damsgaard, A., Egholm, D. L., Piotrowski, J. A., Tulaczyk, S., Larsen, N. K., and Tylmann, K.: Discrete element modeling of subglacial sediment deformation, J. Geophys. Res.-Earth, 118, 2230-2242, 2013.

De Angelis, H. and Skvarca, P.: Glacier surge after ice shelf collapse, Science, 299, 1560-1562, 2003.

Dewhurst, D. N., Brown, K. M., Clennell, M. B., and Westbrook, G. K.: A comparison of the fabric and permeability anisotropy of consolidated and sheared silty clay, Eng. Geol., 42, 253-267, 1996.

Di Felice, R.: The voidage function for fluid-particle interaction systems, Int. J. Multiphas. Flow, 20, 153-159, 1994.

Dupont, T. K. and Alley, R. B.: Assessment of the importance of ice-shelf buttressing to ice-sheet flow, Geophys. Res. Lett., 32, L04503, doi:10.1029/2004GL022024, 2005.

Engelhardt, H. and Kamb, B.: Basal sliding of ice stream B, West Antarctica, J. Glaciol., 44, 223-230, 1998.

Ergun, S.: Fluid flow through packed columns, Chem. Eng. Prog., 43, 89-94, 1952.

Feng, Y. Q. and Yu, A. B.: Assessment of model formulations in the discrete particle simulation of gas-solid flow, Ind. Eng. Chem., 43, 8378-8390, 2004.

Ferziger, J. H. and Perić, M.: Computational Methods for Fluid Dynamics, vol. 3, Springer, Berlin, 2002.

Fischer, U. H. and Clarke, G. K. C.: Review of subglacial hydro-mechanical coupling: Trapridge glacier, Yukon Territory, Canada, Quatern. Int., 86, 29-43, 2001.

Fischer, U. H., Porter, P. R., Schuler, T., Evans, A. J., and Gudmundsson, G. H.: Hydraulic and mechanical properties of glacial sediments beneath Unteraargletscher, Switzerland: implications for glacier basal motion, Hydrol. Process., 15, 3525-3540, 2001.

Fowler, A. C.: An instability mechanism for drumlin formation, Geol. Soc., London, Spec. Pub., 176, 307-319, 2000.

GDR-MiDi: On dense granular flows, Eur. Phys. J. E, 14, 341-365, 2004.

Gerya, T.: Introduction to Numerical Geodynamic Modelling, Cambridge University Press, Cambridge, 2010.

Gidaspow, D.: Multiphase Flow and Fluidization, Academic Press, San Diego, 1994.

Gidaspow, D., Bezburuah, R., and Ding, J.: Hydrodynamics of circulating fluidized beds: kinetic theory approach, Tech. Rep., Illi- 
nois Inst. of Tech., Dept. Chemical Engineering, Chicago, IL (United States), 1992.

Goren, L., Aharonov, E., Sparks, D., and Toussaint, R.: The mechanical coupling of fluid-filled granular material under shear, Pure Appl. Geophys., 168, 2289-2323, 2011.

$\mathrm{Gu}$, Y., Chialvo, S., and Sundaresan, S.: Rheology of cohesive granular materials across multiple dense-flow regimes, Phys. Rev. E, 90, 032206, doi:10.1103/PhysRevE.90.032206, 2014.

Harleman, D. R. F., Mehlhorn, P. F., and Rumer, R. R.: Dispersionpermeability correlation in porous media, J. Hydr. Eng. Div.ASCE, 89, 67-85, 1963.

Hazen, A.: Discussion of dams on sand formation, T. Am. Soc. Civ. Eng., 73, 199-221, 1911.

Henderson, A., Ahrens, J., and Law, C.: The ParaView Guide, Kitware, Clifton Park, NY, 2007.

Hindmarsh, R. C. A.: The stability of a viscous till sheet coupled with ice flow, considered at wavelengths less than the ice thickness, J. Glaciol., 44, 285-292, 1998.

Hooke, R. L. and Iverson, N. R.: Grain-size distribution in deforming subglacial tills: role of grain fracture, Geology, 23, 57-60, 1995.

Hoomans, B. P. B., Kuipers, J. A. M., Briels, W. J., and Van Swaaij, W. P. M.: Discrete particle simulation of bubble and slug formation in a two-dimensional gas-fluidised bed: a hardsphere approach, Chem. Eng. Sci., 51, 99-118, 1996.

Hunter, J. D.: Matplotlib: a 2D graphics environment, Comput. Sci. Eng., 9, 90-95, 2007.

Hutter, K., Svendsen, B., and Rickenmann, D.: Debris flow modeling: a review, Continuum Mech. Therm., 8, 1-35, 1994.

Iverson, N. R.: Coupling between a glacier and a soft bed: II. Model results, J. Glaciol., 45, 41-53, 1999.

Iverson, N. R.: Shear resistance and continuity of subglacial till: hydrology rules, J. Glaciol., 56, 1104-1114, 2010.

Iverson, N. R., Jansson, P., and Hooke, R. L.: In-situ measurement of the strength of deforming subglacial till, J. Glaciol., 40, 497503, 1994.

Iverson, N. R., Hooyer, T. S., and Hooke, R. L.: A laboratory study of sediment deformation: stress heterogeneity and grain-size evolution, Ann. Glaciol., 22, 167-175, 1996.

Iverson, N. R., Baker, R. W., and Hooyer, T. S.: A ring-shear device for the study of till deformation: tests on tills with contrasting clay contents, Quaternary Sci. Rev., 16, 1057-1066, 1997a.

Iverson, R. M., Reid, M. E., and LaHusen, R. G.: Debris-flow mobilization from landslides, Ann. Rev. Earth Pl. Sc., 25, 85-138, 1997b.

Iverson, N. R., Hooyer, T. S., and Baker, R. W.: Ring-shear studies of till deformation: Coulomb-plastic behavior and distributed strain in glacier beds, J. Glaciol., 148, 634-642, 1998.

Iverson, R. M., Reid, M. E., Iverson, N. R., LaHusen, R. G., Logan, M., Mann, J. E., and Brien, D. L.: Acute sensitivity of landslide rates to initial soil porosity, Science, 290, 513-516, 2000.

Iverson, N. R., Mann, J. E., and Iverson, R. M.: Effects of soil aggregates on debris-flow mobilization: Results from ring-shear experiments, Eng. Geol., 114, 84-92, 2010.

Jajcevic, D., Siegmann, E., Radeke, C., and Khinast, J. G.: Largescale CFD-DEM simulations of fluidized granular systems, Chem. Eng. Sci., 98, 298-310, 2013.

Joughin, I., Fahnestock, M., MacAyeal, D., Bamber, J. L., and Gogineni, P.: Observation and analysis of ice flow in the largest Green- land ice stream, J. Geophys. Res.-Atmos., 106, 34021-34034, 2001.

Kamb, B.: Glacier surge mechanism based on linked cavity configuration of the basal water conduit system, J. Geophys. Res., 92, 9083-9100, 1987.

Kamb, B.: Rheological nonlinearity and flow instability in the deforming bed mechanism of ice stream motion, J. Geophys. Res. 96, 16585-16595, 1991.

Kavanaugh, J. L. and Clarke, G. K. C.: Discrimination of the flow law for subglacial sediment using in situ measurements and an interpretation model, J. Geophys. Res.-Earth, 111, F01002, doi:10.1029/2005JF000346, 2006.

Kloss, C., Goniva, C., Hager, A., Amberger, S., and Pirker, S.: Models, algorithms and validation for opensource DEM and CFDDEM, Prog. Comput. Fluid Dy., 12, 140-152, 2012.

Kozeny, J.: Ueber kapillare Leitung des Wassers im Boden, Sitzber. Aka. Wiss. Wien, 136, 271-306, 1927.

Krumbein, W. C. and Monk, G. D.: Permeability as a function of the size parameters of unconsolidated sand, T. Am. I. Min. Met. Eng., 151, 153-163, 1943.

Kyrke-Smith, T. M., Katz, R. F., and Fowler, A. C.: Subglacial hydrology and the formation of ice streams, P. R. Soc. A, 470, 20130494, doi:10.1098/rspa.2013.0494, 2014.

Luding, S.: Introduction to discrete element methods: basic of contact force models and how to perform the micro-macro transition to continuum theory, Eur. J. Env. Civ. Eng., 12, 785-826, 2008.

MacAyeal, D. R., Bindschadler, R. A., and Scambos, T. A.: Basal friction of Ice Stream E, West Antarctica, J. Glaciol., 41, 247$262,1995$.

Mair, K. and Hazzard, J. F.: Nature of stress accommodation in sheared granular material: insights from 3D numerical modeling, Earth Planet. Sc. Lett., 259, 469-485, 2007.

Mair, K., Frye, K. M., and Marone, C.: Influence of grain characteristics on the friction of granular shear zones, J. Geophys. Res.Sol. Ea., 107, ECV-4, doi:10.1029/2001JB000516, 2002.

Mangeney, A., Tsimring, L. S., Volfson, D., Aranson, I. S., and Bouchut, F.: Avalanche mobility induced by the presence of an erodible bed and associated entrainment, Geophys. Res. Lett., 34, L22401, doi:10.1029/2007GL031348, 2007.

McNamara, S., Flekkøy, E. G., and Måløy, K. J.: Grains and gas flow: molecular dynamics with hydrodynamic interactions, Phys. Rev. E, 61, 4054-4059, 2000.

Mead, W. J.: The geologic role of dilatancy, J. Geol., 33, 685-698, 1925.

Mitchell, J. K. and Soga, K.: Fundamentals of Soil Behavior, Wiley, New York, 2005.

Moore, P. L. and Iverson, N. R.: Slow episodic shear of granular materials regulated by dilatant strengthening, Geology, 30, 843846, 2002.

Morgan, J. K.: Numerical simulations of granular shear zones using the distinct element method 2. Effects of particle size distribution and interparticle friction on mechanical behavior, J. Geophys. Res., 104, 2721-2732, 1999.

Mutabaruka, P., Delenne, J.-Y., Soga, K., and Radjai, F.: Initiation of immersed granular avalanches, Phys. Rev. E, 89, 052203, doi:10.1103/PhysRevE.89.052203, 2014.

NVIDIA: CUDA C Programming Guide, NVIDIA Corporation, Santa Clara, CA, USA, 5.0 Edn., 2013. 
Odar, F.: Verification of proposed equation for calculation of forces on a sphere accelerating in a viscous fluid. J. Fluid. Mech., 25, 591-592, 1966.

Odar, F., and Hamilton, W., S.: Forces on a sphere accelerating in a viscous fluid, J. Fluid. Mech., 18, 302-314, 1964.

Pailha, M., Nicolas, M., and Pouliquen, O.: Initiation of underwater granular avalanches: influence of the initial volume fraction, Phys. Fluids, 20, 111701, doi:10.1063/1.3013896, 2008.

Patankar, S. V.: Numerical Heat Transfer and Fluid Flow, CRC Press, Boca Raton, Florida, USA, 1980.

Piotrowski, J. A.: Genesis of the Woodstock drumlin field, southern Ontario, Canada, Boreas, 16, 249-265, 1987.

Piotrowski, J. A., Larsen, N. K., and Junge, F. W.: Reflections on soft subglacial beds as a mosaic of deforming and stable spots, Quaternary Sci. Rev., 23, 993-1000, 2004.

Press, W. H., Teukolsky, S. A., Vetterling, W. T., and Flannery, B. P.: Numerical Recipes 3rd edition: the Art of Scientific Computing, Cambridge University Press, Cambridge, UK, 2007.

Price, S. F., Bindschadler, C. L., Hulbe, C. L., and Blankenship, D. D.: Force balance along an inland tributary and onset to Ice Stream D, West Antarctica, J. Glaciol., 48, 20-30, 2002.

Radjaï, F., and Dubois, F.: Discrete-Element Modeling of Granular Materials, Wiley-Iste, Hoboken, New Jersey, USA, 2011.

Rathbun, A. P., Marone, C., Alley, R. B., and Anandakrishnan, S.: Laboratory study of the frictional rheology of sheared till, J. Geophys. Res., 113, F02020, doi:10.1029/2007JF000815, 2008.

Reynolds, O.: On the dilatancy of media composed of rigid particles in contact, Philos. Mag., 20, 469-481, 1885.

Rignot, E. and Thomas, R. H.: Mass balance of polar ice sheets, Science, 297, 1502-1506, 2002.

Rignot, E., Casassa, G., Gogineni, P., Krabill, W., Rivera, A., and Thomas, R.: Accelerated ice discharge from the Antarctic Peninsula following the collapse of Larsen B ice shelf, Geophys. Res. Lett., 31, L18401, doi:10.1029/2004GL020697, 2004.

Rondon, L., Pouliquen, O., and Aussillous, P.: Granular collapse in a fluid: role of the initial volume fraction, Phys. Fluids, 23, 073301, doi:10.1063/1.3594200, 2011.

Rubinow, S. I. and Keller, J. B.: The transverse force on a spinning sphere moving in a viscous fluid, J. Fluid. Mech., 11, 447-459, 1961.

Saffman, P. G.: Lift on a small sphere in slow shear flow, J. Fluid. Mech., 22, 385-400, 1965.

Saffman, P. G.: Corrigendum to "Lift on a small sphere in slow shear flow”, J. Fluid. Mech., 31, 624, 1968.

Schellart, W. P.: Shear test results for cohesion and friction coefficients for different granular materials: scaling implications for their usage in analogue modelling, Tectonophysics, 324, 1-16, 2000.

Schofield, A. N. and Wroth, P.: Critical State Soil Mechanics, McGraw-Hill, London, 1968.

Schwartz, F. W. and Zhang, H.: Fundamentals of Ground Water, Wiley, New York, 2003.

Sergienko, O. V. and Hindmarsh, R. C. A.: Regular patterns in frictional resistance of ice-stream beds seen by surface data inversion, Science, 342, 1086-1089, 2013.

Stokes, C. R., Clark, C. D., Lian, O. B., and Tulaczyk, S.: Ice stream sticky spots: a review of their identification and influence beneath contemporary and palaeo-ice streams, Earth-Sci. Rev., 81, 217$249,2007$.
Thomas, R., Rignot, E., Casassa, G., Kanagaratnam, P., Acuña, C., Akins, T., Brecher, H., Frederick, E., Gogineni, P., Krabill, W., Manizade, S., Ramamoorthy, H., Rivera, A., Russell, R., Sonntag, J., Swift, R., Yungel, J., and Zwally, J.: Accelerated sealevel rise from West Antarctica, Science, 306, 255-258, 2004.

Thomason, J. F. and Iverson, N. R.: A laboratory study of particle ploughing and pore-pressure feedback: a velocity-weakening mechanism for soft glacier beds, J. Glaciol., 54, 169-181, 2008.

Topin, V., Dubois, F., Monerie, Y., Perales, F., and Wachs, A.: Micro-rheology of dense particulate flows: application to immersed avalanches, J. Non-Newton. Fluid, 166, 63-72, 2011.

Truffer, M., Harrison, W. D., and Echelmeyer, K. A.: Glacier motion dominated by processes deep in underlying till, J. Glaciol., 46, 213-221, 2000.

Tsuji, T., Kawaguchi, T., and Tanaka, T.: Discrete particle simulation of 2-dimensional fluidized-bed, Powder Technol., 77, 79-87, 1993.

Tsuji, Y., Tanaka, T., and Ishida, T.: Lagrangian numerical simulation of plug flow of cohesionless particles in a horizontal pipe, Powder Technol., 71, 239-250, 1992.

Tulaczyk, S.: Ice sliding over weak, fine-grained tills: dependence of ice-till interactions on till granulometry, Geol. Soc. Am. Mem., 337, 159-177, 1999.

Tulaczyk, S., Kamb, W. B., and Engelhardt, H. F.: Basal mechanics of ice stream B, West Antarctica I. Till mechanics, J. Geophys. Res., 105, 463-481, 2000a.

Tulaczyk, S., Kamb, W. B., and Engelhardt, H. F.: Basal mechanics of ice stream B, West Antarctica II. Undrained plastic-bed model, J. Geophys. Res., 105, 483-494, 2000 b.

Turrin, J. B., Forster, R. R., Sauber, J. M., Hall, D. K., and Bruhn, R. L.: Effects of bedrock lithology and subglacial till on the motion of Ruth Glacier, Alaska, deduced from five pulses from 1973 to 2012, J. Glaciol., 60, 771-781, doi:10.3189/2014JoG13J182, 2014.

Wang, B., Chu, K. W., and Yu, A. B.: Numerical study of particlefluid flow in a hydrocyclone, Ind. Eng. Chem., 46, 4695-4705, 2007.

Wen, C. and Yu, Y.: Mechanics of fluidization, Chem. Eng. Prog., 62, 100-111, 1966.

Whillans, I. M. and van der Veen, C. J.: The role of lateral drag in the dynamics of Ice Stream B, Antarctica, J. Glaciol., 43, 231237, 1997.

Winberry, J. P., Anandakrishnan, S., Alley, R. B., Bindschadler, R. A., and King, M. A.: Basal mechanics of ice streams: insights from the stick-slip motion of Whillans Ice Stream, West Antarctica, J. Geophys. Res., 114, F01016, doi:10.1029/2008JF001035, 2009.

Xu, B. H. and Yu, A. B.: Numerical simulation of the gas-solid flow in a fluidized bed by combining discrete particle method with computational fluid dynamics, Chem. Eng. Sci., 52, 2785-2809, 1997.

Xu, B. H., Feng, Y. Q., Yu, A. B., Chew, S. J., and Zulli, P.: A numerical and experimental study of the gas-solid flow in a fluid bed reactor, Powder Handling and Processing, 13, 71-76, 2001.

Zhou, Z. Y., Kuang, S. B., Chu, K. W., and Yu, A. B.: Discrete particle simulation of particle-fluid flow: model formulations and their applicability, J. Fluid Mech., 661, 482-510, 2010. 
Zhu, H. P., Zhou, Z. Y., Yang, R. Y., and Yu, A. B.: Discrete particle simulation of particulate systems: theoretical developments, Chem. Eng. Sci., 62, 3378-3396, 2007. 